Original Research Paper

\title{
Spatial Analysis and Modeling the Nitrogen Flush after Rainfall Events at the Field Scale in SWAT
}

\author{
${ }^{1}$ Elizabeth Brooke Haney, ${ }^{2}$ Richard Lee Haney, ${ }^{2}$ Jeffrey George Arnold, \\ ${ }^{2}$ Michael James White, ${ }^{3}$ Raghavan Srinivasan and ${ }^{4}$ Scott Allen Senseman \\ ${ }^{I}$ Texas Agri Life Research and Extension Center, Texas A\&M University, 720 E. Blackland Road, Temple, TX 76502, USA \\ ${ }^{2}$ USDA-ARS, Grassland, Soil and Water Research Laboratory, 808 East Blackland Road, Temple, TX 76502, USA \\ ${ }^{3}$ Department of Ecosystem Science and Management, Texas A\&M University, 2138 TAMU, College Station, TX, 77843, USA \\ ${ }^{4}$ Department of Plant Sciences, University of Tennessee, 2431 Joe Johnson Dr., Knoxville, TN, 37996, USA
}

Article history

Received: 21-01-2016

Revised: 21-03-2016

Accepted: 22-03-2016

Corresponding Author: Elizabeth Brooke Haney

Texas A\&M University, Texas

Agri Life Research and

Extension Center, 720 E.

Blackland Road, Temple, TX

76502, USA

$\mathrm{Ph}: 254-770-6560$;

Fax: 254-770-6561

Email: lhaney@brc.tamus.edu

\begin{abstract}
Current nitrogen (N) models tend to neglect the contribution of the microbial population to the plant available $\mathrm{N}$ pool, resulting in an underestimation of yield and possible over or underestimation of $\mathrm{N}$ runoff from natural and agricultural landscapes. We used the measurement of microbial activity coupled with the measurement of their food source, water extractable nitrogen $(\mathrm{N})$ and carbon $(\mathrm{C})$, to add a flush of $\mathrm{N}$ after rainfall events in the Soil Water Assessment Tool (SWAT). Soil test data and spatial analysis of $\mathrm{N}$ mineralization values were used to: (1) Quantify spatial variation of water extractable organic and inorganic $\mathrm{N}$, soil inorganic $\mathrm{N}$ and microbial activity; (2) develop a field scale model to determine $\mathrm{N}$ mineralization using updated soil testing methods for integration into the SWAT model; and (3) predict wheat yield. Simulation results indicate that yearly yield values and the variability of these yield values were consistently greater from the modified $\mathrm{N}$ model than from the SWAT model, as would be expected with the addition of $\mathrm{N}$ mineralization resulting from microbial activity. The spatial variability in yield results increased with the modified $\mathrm{N}$ model as compared to the SWAT model. The yield data resulting from the modified $\mathrm{N}$ model simulation were sensitive to soil nutrient values as well as variations in elevation. Temporal and climatic variability is accounted for by including a precipitation trigger for $\mathrm{N}$ mineralization. The equations used to model the complex biogeochemical $\mathrm{N}$ cycling relationships are elegant in their simplicity, yet capture the spatial complexity associated with their processes. The modified $\mathrm{N}$ model may be useful to regulators to help with the simulation of new conservation practices that include the effect of lower fertilizer inputs on nutrient runoff and pollution.
\end{abstract}

Keywords: Soil and Water Assessment Tool, SWAT, Nitrogen Modeling, Spatial and Temporal Modeling of Nitrogen Cycling, Soil Nutrient Cycling Modeling

\section{Introduction}

All of the major components of environmental modeling have spatial distributions and these distributions affect biogeochemical processes. A Geographic Information System (GIS) is an important tool in describing the spatial characteristics of the environment, while environmental modeling simulates the environmental processes affected by the spatial distribution (Rao et al., 2000). Models can be used on a large scale to shape policy, like the Conservation Effects
Assessment Program (CEAP) Hydrologic Unit Model for the United States/Soil Water Assessment Tool (HUMUS/SWAT) model. The HUMUS system improves on existing technologies for making national and regional water resource assessment considering both current and projected management conditions. The HUMUS system is conducted at the watershed scale using a Geographic Information System (GIS) to collect, manage, analyze and display the spatial and temporal inputs and outputs and relational databases for managing the non-spatial data (Arnold et al., 2010). Other models, 
such as CENTURY, were developed to analyze longterm changes in $\mathrm{N}$ and $\mathrm{C}$ in soil in various ecosystems on a farm or regional scale (Metherell et al., 1993). On a field, farm or small watershed scale, the Agricultural Policy/Environmental Extender Model (APEX) simulates $\mathrm{N}$ dynamics with varying land management strategies, such as different nutrient management practices, tillage operations and alternative cropping systems.

Many nitrogen mineralization models, including the Environmental Policy Integrated Climate Model (EPIC), on which the $\mathrm{N}$ cycling in SWAT is based on, are based on the Production of arid Pastures limited by RAinfall and Nitrogen (PAPRAN) model (Lauenroth et al., 1983; Neitsch et al., 2001; Matthews and Stephens, 2002; Seligman and van Keulen, 1981; Williams, 1995). The PAPRAN model considers two sources of mineralization, fresh organic $\mathrm{N}$ associated with crop residue and microbial biomass and the stable organic $\mathrm{N}$ associated with the soil humic fraction. In general, these mineralization processes take into account the $\mathrm{C}: \mathrm{N}$ ratio of the soil, temperature, soil water content and sometimes soil $\mathrm{C}: \mathrm{P}$ ratios. Mineralization is estimated as a function of organic $\mathrm{N}$ weight, soil water and temperature. The incorporated PAPRAN model does not account for the contribution of the microbial population to the plant available $\mathrm{N}$ pool, resulting in an underestimation of yield and possible over or underestimation of $\mathrm{N}$ runoff from natural systems and agricultural landscapes that are not conventionally tilled. We must accurately assess the microbial biomass and their activity since they are the main drivers of $\mathrm{N}$ cycling and soil fertility in general (Fig. 1).

Over the years our technological capabilities have increased and now we can observe microbiological processes in the soil on more localized physical and temporal scales. Microbes exist in soil in great abundance and their composition, adaptability and structure are a result of the environment they inhabit. Microbes have adapted to temperature and moisture levels, soil structure, crop and management inputs, as well as soil nutrient content. Since soil microbes are driven by their need to reproduce and by their need for acquiring $\mathrm{C}, \mathrm{N}$ and $\mathrm{P}$ in a ratio of 100: 10: $1(\mathrm{C}: \mathrm{N}: \mathrm{P})$, it is safe to assume that soil microbes are a dependable indicator of $\mathrm{N}$ cycling in the soil (Franzluebbers et al., 1996). It is well established that $\mathrm{C}$ is the driver of the soil nutrient-microbial recycling system (Paul and Juma, 1981; Tate, 1995; Bengtsson et al., 2003). The consistent need for $\mathrm{C}$ and $\mathrm{N}$ sets the stage for a standardized, universal measurement of soil microbial activity. Since soil microbes take in oxygen and release $\mathrm{CO}_{2}$, we can couple this mechanism to their activity. It follows that soil microbial activity is a response to the level of soil quality/fertility in which they find themselves and we can now also assess a real-time snapshot of the active microbial population using a measurement of microbial respiration.

The measurement of microbial activity, coupled with the measurement of their food source, water extractable $\mathrm{N}$ and $\mathrm{C}$, which are broken down by soil microbes and released to the soil in plant available inorganic $\mathrm{N}$ forms, provide the initial $\mathrm{N}$ values and the mineralization rate necessary to modify $\mathrm{N}$ cycling routines. Using soil test data and spatial analysis $\mathrm{N}$ mineralization values are determined based on the relationships between water extractable $\mathrm{N}$ and $\mathrm{C}$ as well as microbial activity.

The objective of this study was to: (1) Quantify spatial variation of water extractable organic and inorganic $\mathrm{N}$, soil inorganic $\mathrm{N}$ and microbial activity using updated soil-testing methods; (2) develop a field scale model to determine $\mathrm{N}$ mineralization for integration into the SWAT model; (3) use GIS to collect and analyze spatial and temporal inputs and outputs; and (4) predict wheat yield based on objectives 1,2 and 3.

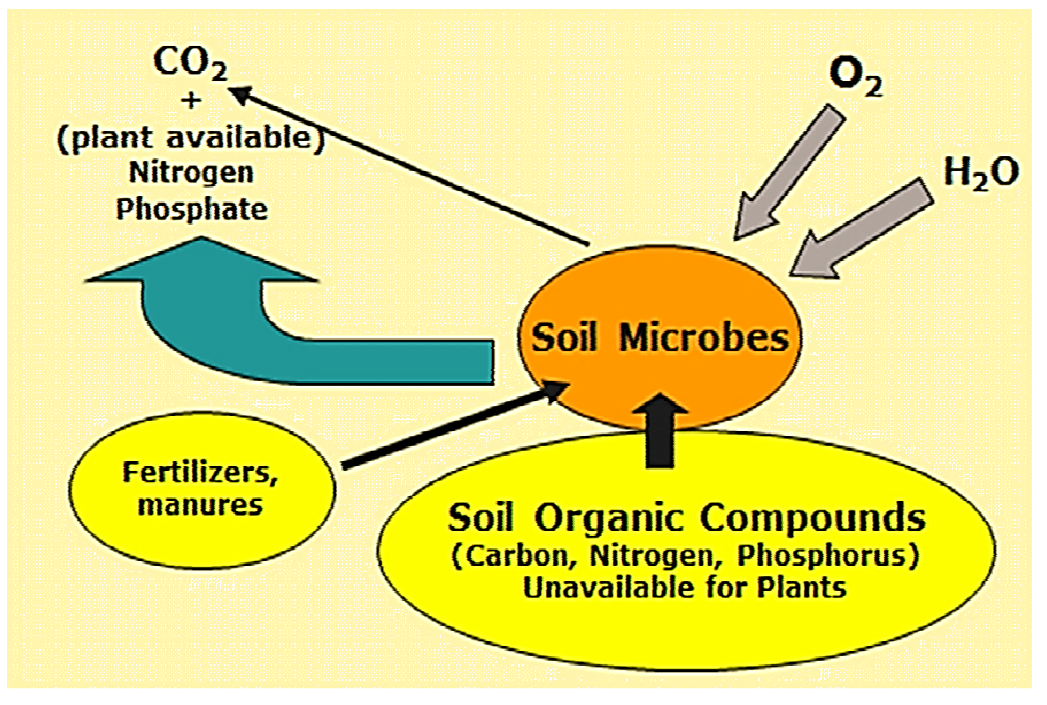

Fig. 1. Soil microbes acting on soil organic matter to release $\mathrm{N}$ 


\section{Materials and Methods}

Research was conducted at a research field at the United States Department of Agriculture, Agricultural Research Service (USDA/ARS) Facility in Temple, Bell County, TX (3109' 09", -97 24' 28", elevation: 205 m) in the Texas Blackland Prairies ecoregion. The climate is humid subtropical with a mean annual temperature of $19^{\circ} \mathrm{C}$ and mean annual precipitation of $886 \mathrm{~mm}$. Rainfall occurs year-round with hot summers and moderate seasonality. The field where the study was conducted consists of 33.6 ha that has been in consecutive cover/cash crop rotation for 5 years. Cash crop rotations consist of wheat and sorghum. Cover crops consist of a mixture of legumes and forbs. Soils consist of Austin Silty Clay 1 to 5\% slopes and Houston Black Clay 1 to 3\% slopes (Fig. 2 ). At the time of sampling, the entire field had been planted in cover crops consisting of a mixture of legumes and forbs. The cover crop had not fully emerged, leaving large portions of the field that were either bare or covered with residue. The last three crops grown on the field were wheat in winter of 2011 and sorghum in the summers of 2012 and 2013.

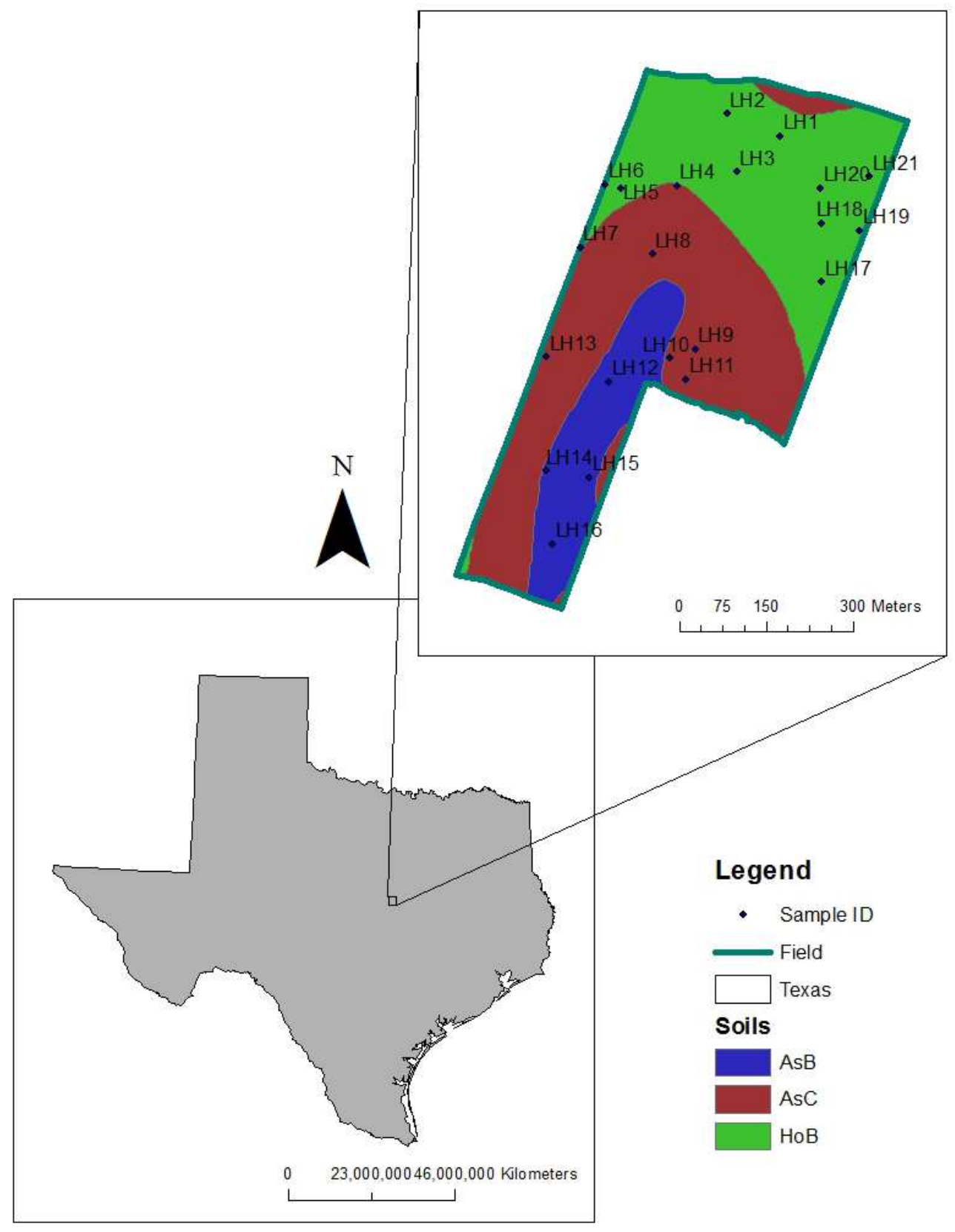

Fig. 2. Soils within field of study 
All GIS analyses were conducted using ArcGIS 10.0 (ESRI, 2011). Information extraction and spatial analyses were performed using ArcGIS 10.0.

Daily weather data were obtained from the weather station located at the USDA-ARS, Grassland, Soil and Water Research Laboratory in Temple, TX (www.ars.usda.gov/Research/docs.htm?docid=9697).

Data include maximum and minimum air temperature and total precipitation. Daily weather data were utilized to perform model runs on a daily time step to determine yield from the field of study from 1980 to 2004. The model was validated using weather data from 2011 and 2012. Weather data are used in the model to predict the daily fluxes of $\mathrm{N}$ as well as plant growth for yield simulation.

The digital elevation model used for analyses is from the National Aeronautics and Space Administration (NASA) Shuttle Radar Topography Mission (SRTM) and was obtained from United States Geological Survey (USGS) Earth Explorer (earthexplorer.usgs.gov). Elevation models were arranged into tiles covering a degree latitude and longitude with an arcsecond or $30 \mathrm{~m}$ resolution. The data used are void filled using primarily Advanced Space borne Thermal Emission and Reflection Radiometer Global Digital Elevation Model version 2 (ASTER GDEM2) and secondly the USGS National Elevation Dataset. The SRTM Digital Elevation Model (DEM) was used to develop $2 \mathrm{~m}$ elevation contours for determining soil samples locations. Contours were constructed using the Contour toolset in ArcGIS 10, ArcToolbox.

Soil sample points at least $100 \mathrm{~m}$ apart were randomly chosen based on $2 \mathrm{~m}$ elevation contours as the constraining feature class (create random points) resulting in 21 points for the entire field. Soil samples from the top $15 \mathrm{~cm}$ of the upper soil profile were obtained at each sample point. The top $15 \mathrm{~cm}$ of soil were chosen since the majority of $\mathrm{N}$ cycling occurs at this depth. Each soil sample was dried at $50^{\circ} \mathrm{C}$, ground to pass a $2 \mathrm{~mm}$ sieve and weighed into two $50 \mathrm{ml}$ centrifuge tubes ( $4 \mathrm{~g}$ each) and one $50 \mathrm{~mL}$ plastic beakers $(40 \mathrm{~g}$ each) that was perforated to allow water to be lifted by the soil. Soil samples are naturally able to reach field capacity through capillary action (Haney and Haney, 2010). One $4 \mathrm{~g}$ sample was extracted with 40 $\mathrm{mL}$ of DI water and the other with $\mathrm{H} 3 \mathrm{~A}$ extract ant (Haney et al., 2010). The samples were shaken for 10 min, centrifuged for $5 \mathrm{~min}$ and filtered through Whatman $2 \mathrm{~V}$ filter paper. The water and $\mathrm{H} 3 \mathrm{~A}$ extracts were analyzed on a Seal Analytical rapid flow analyzer for $\mathrm{NO}_{3}-\mathrm{N}$ and $\mathrm{NH}_{4}-\mathrm{N}$. The water extract was also analyzed on a Teledyne-Tekmar Apollo $9000 \mathrm{C}$ : $\mathrm{N}$ analyzer for water-extractable organic $\mathrm{C}$ and total Water Extractable N (WEN). Water Extractable Organic N (WEON) was determined from the difference of total water extractable $\mathrm{N}$ and water extractable $\mathrm{NO}_{3}-\mathrm{N}$ and $\mathrm{NH}_{4}-\mathrm{N}$.

One-day $\mathrm{CO}_{2}$ evolution was determined using the Solvita Gel System (Haney et al., 2008). The Solvita Gel System quantifies the relative differences in $\mathrm{CO}_{2}$ respiration after drying and rewetting using a $\mathrm{pH}$ sensitive gel paddle and digital color reader that incorporates diode array detection technology that selects the intensity of red, blue and green emission. Samples were weighed $(40 \mathrm{~g})$ and wetted to field capacity using capillary action. Wetted samples were placed into 8 -oz jars with lids accompanied by a Solvita gel paddle. The samples were incubated at $25^{\circ} \mathrm{C}$ for 1 day. After 1 day, the paddles were removed and placed in the Solvita digital reader for analysis of $\mathrm{CO}_{2}$ concentration. The resulting data were used for the spatial analysis of $\mathrm{N}$ values throughout the field for ultimate use in the $\mathrm{N}$ cycling model.

Satellite imagery was obtained from the National Agriculture Imagery Program (NAIP) through the Texas Natural Resource Information System (TNRIS, www.tnris.org). The $1 \mathrm{~m}$ digital ortho rectified image was taken on June 28, 2012, during the summer growing season. Imagery during the winter wheat growing season was unavailable at the resolution necessary to perform analysis on the field of study; however, mixed cover crops were growing on the entire field at the time the imagery was obtained. The NAIP imagery contains 4 bands (red, green, blue and infrared). The aerial photograph was utilized to delineate the field, which was ground truthed by walking the delineated line while running the ArcGIS mobile application on an iPhone 5S. In addition, the aerial photo taken in 2012 was used to calculate the Normalized Difference Vegetation Index (NDVI) in ArcGIS 10.0. The final NDVI image was used to assess the validity of the output of the model simulations. The aerial photo was used to calculate the Normalized Difference Vegetation Index (NDVI) (Rouse et al., 1973) in ArcGIS 10.0 as follows Equation 1:

$N D V I=((I R-R) /(I R+R)) * 100+100$

where, $I R$ is the infrared band and $R$ is the red band. The output values range from 0 to 200 , with 200 indicating the greenest and most healthy vegetation and 0 representing dead vegetation or bare soil. The NDVI is preferred for vegetation monitoring as it naturally compensates for changing illumination conditions, surface slope, aspect and other extraneous factors (Lillesand et al., 2004). The final NDVI image was used to validate the output of the model simulations.

Descriptive statistical analyses, correlations and regressions were performed using Sigma Plot Version 
12.5 for Windows (SSI, 2012) and Curve Expert Profession v2.0.4 (Hyams, 2013). Kriging was used in ArcGIS 10.0 (ESRI, 2011) for spatial interpolation of values at unsampled locations based on sample data and their spatial structure determined using Moran's I analysis. Pearson product-moment correlation coefficients were determined between soil yield results using the modified $\mathrm{N}$ model, yield results from the SWAT mode land NDVI using PASSaGE 2 (Rosenberg and Anderson, 2011). Because spatial autocorrelation in the model output variables affects does not meet the assumptions of classical tests of significance of correlation and regression coefficients, the statistical significance of these relationships was determined by Dutilleul's modified t test (Legendre et al., 2002) which accounts for thee effects of spatial autocorrelation. Dutilleul's modified $t$ tests were conducted using PASSaGE 2 (Rosenberg and Anderson, 2011).

\section{Model Theory}

The basic model structure was developed using the measured Water-Extractable Organic C (WEOC) and N (WEON) and 1-d $\mathrm{CO}_{2}$ analysis, as well as scientific knowledge regarding the interactions between soil microbes and water extractable $\mathrm{C}$ and $\mathrm{N}$ in the soil. The interactions between the biology of the soil and the inorganic components of the soil are predictable and can be easily modeled using the soil test data we obtained.

Haney et al. (2012) found that soil microbial activity measured as the flush of 1-d $\mathrm{CO}_{2}$ following rewetting of dried soil was significantly correlated to WEOC and WEON. Figure 3 depicts the relationships between 1-d $\mathrm{CO}_{2}$, WEOC and WEON values for various soils throughout the contiguous United States (data from USDAARS). Short-term $C$ respiration from soil after drying and rewetting is also highly correlated with soil microbial biomass $\mathrm{C}$ and 24-d N mineralization (Haney et al., 2012).

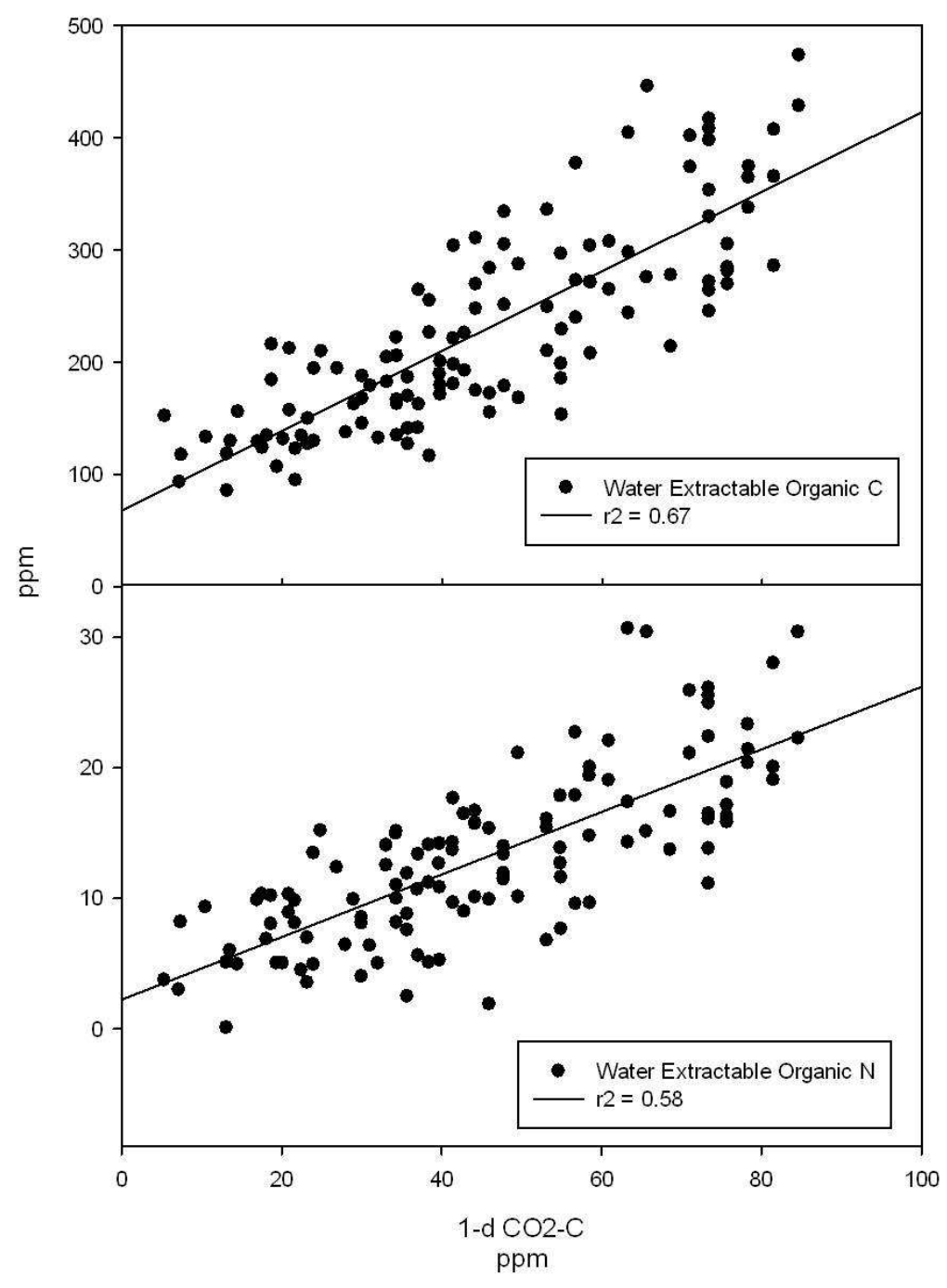

Fig. 3. Relationships between 1- $\mathrm{d} \mathrm{CO}_{2}-\mathrm{C}$ and water extractable $\mathrm{N}$ and $\mathrm{C}$ 
The laboratory Drying and Rewetting (D/R) process mimics the natural processes in the field that occur with rainfall events, the extent of which depends upon climatic and soil conditions. The mineralization of $\mathrm{C}$ and $\mathrm{N}$ following drying/rewetting can be used to quantify the portion of the soil microbial biomass that is most responsive to rainfall events, which can have a strong impact on nutrient availability (Franzluebbers et al., 2000). Specifically, every time it rains and the soil gets wet to a certain degree of field capacity, microbes activate, reproduce, eat long-chain organic molecules containing $\mathrm{C}, \mathrm{N}$ and $\mathrm{P}$ and in the process, convert organic $\mathrm{N}$ to plant available $\mathrm{N}$. The pulse of $\mathrm{C}, \mathrm{N}$ and $\mathrm{P}$ can be 10 to 100 times the background level of turnover following rainfall after a dry period (Haney et al., 2010). Given that soil microbes drive $\mathrm{N}$ mineralization, 1-day $\mathrm{CO}_{2}$ evolution after $\mathrm{D} / \mathrm{R}$ may be used to simulate the soil's ability to supply N (Haney and Haney, 2010).

In the model we used 1-d $\mathrm{CO}_{2}$ values and WEOC concentrations to determine the Microbially Active $\mathrm{C}$ (MAC) pool using the following Equation 2:

$M A C=1-d \mathrm{CO}_{2} / W E O C$

where, WEOC is the measurable pool of water extractable organic $C$ that is the food source for microbial activity measured as 1- $d \mathrm{CO}_{2}$. The quantity of available substrate ( $\mathrm{C}$ and $\mathrm{N}$ ) available for mineralization is measured using the MAC ratio.

Schimel and Bennett (2004) make a strong case for rethinking our approach to estimating $\mathrm{N}$ mineralization by also considering the contribution of $\mathrm{N}$ from the watersoluble organic $\mathrm{N}$ pool. The model considers the basic $\mathrm{C}$ : $\mathrm{N}$ relationship that exists in organic matter and simulated the WEON pool as being accessed directly by the microbes and in proportion to MAC. For example, if microbes release $25 \%$ of the $\mathrm{C}$ through respiration, $25 \%$ of the WEON pool will be released as well. The portion of $\mathrm{N}$ that is released from the WEON is therefore calculated as follows Equation 3:

$$
M A C \_W E O N=W E O N \times M A C
$$

Because the release of $\mathrm{N}$ is triggered by rainfall in nature, in the model, rainfall events trigger the release of MAC_WEON as follows:

If (precipday $>=13$.and. sol_st $(\mathrm{k}, \mathrm{j})<=0.25 *$ sol_sumfc(j)

$\&$.and. $\mathrm{k}<=2$ ) then

sol_weon $(k, j)=\operatorname{sol} \_w e n(\mathrm{k}, \mathrm{j})$ - sol_win $(\mathrm{k}, \mathrm{j})$

$\operatorname{sol}$ _macweon $(\mathrm{k}, \mathrm{j})=$ sol_weon $(\mathrm{k}, \mathrm{j}) *\left(\operatorname{sol} \_\right.$oneday $(\mathrm{k}, \mathrm{j}) /$

\&sol_weoc $(k, j))$

End If where, precipday is the amount of rainfall accumulated on each day (mm), sol $s t(k, j)$ is the soil moisture for the layer based on the percent of field capacity in the field, where $k$ is the layer identifier and $j$ is the field or hydrologic resource unit identifier. $\operatorname{sol} \operatorname{sum} f(j)$ is the field capacity of the soil in the field. $\operatorname{sol} w e o n(k, j)$ is the WEON for the soil layer in the field, $\operatorname{sol}$ wen $(k, j)$ is the total water extractable $\mathrm{N}$ in the field, $\operatorname{sol}_{-} w i n(k, j)$ is the water extractable inorganic $\mathrm{N}$ in the field. sol_macweon $(k, j)$ is the combination of Equation 2 and 3. The computed MAC WEON is then added to the nitrate pool for the soil layer in the field (sol_no3 $(\mathrm{k}, \mathrm{j})$ ) using the following Equation 4:

$\operatorname{sol} \_n o 3(k, j)=\operatorname{sol} \_n o 3(k, j)+$ sol_macweon $(k, j)$

The precipitation trigger is set equal to $13 \mathrm{~mm}$, which is just enough to wet the soil and activate the microbes. In the field, significant pulses of $\mathrm{NO}_{\mathrm{x}}$ emissions from rewetted dried soils have been seen from soils receiving as little as $12 \mathrm{~mm}$ rainfall (Haney et al., 2010) indicating that $13 \mathrm{~mm}$ is an appropriate rainfall level to observe a $\mathrm{N}$ flush. The soil moisture trigger is associated with a percent of field capacity in order to limit the $\mathrm{N}$ mineralization events. For example, if an appreciable rainfall event occurs on day 125 of the year and again on day 126 the soil will not have had sufficient time to complete a $\mathrm{D} / \mathrm{R}$ cycle between those days and we do not want to simulate an additional release of $\mathrm{N}$ on day 126 . It is important to simulate a complete $\mathrm{D} / \mathrm{R}$ cycle in order to mimic the natural $\mathrm{D} / \mathrm{R}$ in the field. During a succession of drying and rewetting events in the lab, a uniform pattern of $\mathrm{CO}_{2}$ evolution was exhibited, which also occurred under field conditions (Birch, 1958). Birch (1959) postulated that the common feature between the evolution of $\mathrm{CO}_{2}$ and $\mathrm{N}$ mineralization after drying/rewetting soil was microbial death and subsequent mineralization. These studies suggest that physical alteration of the soil was not a primary factor for the mineralization of $\mathrm{C}$ and $\mathrm{N}$. The majority of the mineralization of $\mathrm{C}$ and $\mathrm{N}$ after rewetting dried soil is likely due to the death of heat susceptible microbes, death from water induced osmotic shock and further renewal of the microbial population and consumption of the organic $\mathrm{C}$ and $\mathrm{N}$ source. While we could attempt to simulate microbial activity on dry days and the resulting $\mathrm{N}$ mineralization, it is very likely that the baseline activity would be insignificant in the grand schema and have little to no effect on yield predictions.

Nitrogen mineralization is not triggered unless the soil water is less than $25 \%$ of field capacity. By using the field capacity of the soil as a gauge we are accounting for the spatial variability in the physical attributes of the soil. The movement of water in soil is dependent on the combined effects of porosity, gravity, mass flow and 
capillary action. Soil porosity is influenced by texture, structure (e.g., degree of aggregation) and organic-matter content. For example, coarse-textured soils have larger pores than fine-grained soils, which allow for more water flow. Organic matter greatly increases the water-holding capacity of a soil. Capillary action is the natural movement of water using adhesion (attraction to solids) and cohesion forces (attraction between water molecules) and is counterbalanced by the effects of gravity and air pockets. Haney et al. (2008) indicate that microbial activity studies that involve $D / R$ soils use gravimetric water content, soil matric potential, or percentage of Water-Filled Pore Space (WFPS) to achieve sufficient moisture content for peak microbial activity. Furthermore, Haney et al. (2008) indicate that a range of 30 to $70 \%$ WFPS is sufficient for peak microbial activity, which represents roughly $50 \%$ of field capacity (Haney et al., 2004). We used a value of $25 \%$ after calibrating the simulations with known fertilizer to known yield values from our study area.

The model was initialized using the initial inorganic $\mathrm{N}, \mathrm{WEN}, \mathrm{WEOC}$ and $1-\mathrm{d} \mathrm{CO}_{2}$ values obtained from the soil analysis of the 21 fields. Weather data for 1980 to 2004 and slope and elevation values for each soil sample were used as input parameters. We treated each soil sample site as its own hydrologic resource unit for simulation purposes. For each soil sample and the corresponding soil values, we conducted simulations of wheat yield by varying fertilizer rates $(67.2,44.8,33.6$, 22.4 and $0 \mathrm{~kg} \mathrm{~N} / \mathrm{ha}$ ). In addition, one sample dataset was chosen to simulate a fertilizer response curve for 9 different fertilizer rates $(335.6,223.9,167.9,111.9,67.2$, 44.8, 33.6, 22.4 and $0 \mathrm{~kg} \mathrm{~N} / \mathrm{ha}$ ). The model was partially validated using 2 simulations, one for wheat in 2011 and the other for sorghum in 2012. The actual field received no fertilizer, so fertilization was not conducted during the simulations.

Modified model results were compared to the traditional SWAT model simulations using the same parameters described above. The SWAT model currently does not have parameters for WEOC, WEON, or 1-d $\mathrm{CO}_{2}$ results; however, initial soil-test $\mathrm{N}$ and $\mathrm{P}$ values were utilized. A complete description of the theory and equations used in the SWAT model can be found at swat.tamu.edu.

\section{Results}

\section{Soil Data}

The mean initial inorganic $\mathrm{N}$ and $\mathrm{P}$ concentrations were 3.95 and $3.96 \mathrm{mg} \mathrm{kg}^{-1}$, respectively. Total WEN (organic plus inorganic $\mathrm{N}$ ) ranged from 16.00 to 26.09 $\mathrm{mg} \mathrm{kg}{ }^{-1}$, with a mean value of $20.99 \mathrm{mg} \mathrm{kg}^{-1}$. Water extractable inorganic $\mathrm{N}$ values were similar to $\mathrm{H} 3 \mathrm{~A}$ extractable $\mathrm{N}$ values with a mean $\mathrm{N}$ concentration of
$4.11 \mathrm{mg} \mathrm{kg}^{-1}$, with all values ranging between 1.11 and $6.72 \mathrm{mg} \mathrm{kg}^{-1}$. One day $\mathrm{CO}_{2}$ values ranges from 12.27 to $34.26 \mathrm{mg} \mathrm{kg}^{-1}$ with a mean value of $22.34 \mathrm{mg} \mathrm{kg}^{-1}$. Water extractable organic $\mathrm{C}$ values range from 208.91 to $343.65 \mathrm{mg} \mathrm{kg}^{-1}$ with a mean concentration of $246.01 \mathrm{mg} \mathrm{kg}^{-1}$. The mean, standard deviation, standard error, minimum, maximum and median values are reported in Table 1 . Water extractable organic $\mathrm{N}$ was determined by subtracting water extractable inorganic $\mathrm{N}$ from WEN.

To visualize the spatial variability of the soil test data, kriging was performed. The data were first assessed for normality using histograms, then Normal Quantile-Quantile Plots were used to determine their suitability for spatial interpolation. The results indicate that the data were mostly normal, excepting water extractable organic carbon, which appeared more normal after a $\log$ transformation. The data were also analyzed for normality using the Shapiro-Wilk test for normality (Fig. 4). Results from 1-day $\mathrm{CO}_{2}$ analysis were normal according to the Shapiro-Wilk test (WStatistic $=0.986, \mathrm{P}=0.987$, Passed). Water extractable total $\mathrm{N}$ and inorganic $\mathrm{N}$ data were also normal according to the Shapiro-Wilk test (W-Statistic = $0.954, \mathrm{P}=0.412$, Passed and W-Statistic $=0.975, \mathrm{P}=$ 0.846 , Passed, respectively). Water extractable organic $\mathrm{C}$ data were also normal according to the Shapiro-Wilk test, when one extreme outlier was taken out of consideration $(\mathrm{W}-$ Statistic $=0.971, \mathrm{P}=0.780$, Passed $)$. A test that passes indicates that the data matches the pattern expected if the data was drawn from a population with a normal distribution. Interpolation results are best when the data are normally distributed for kriging and co-kriging. Wang et al. (2013) found that $\mathrm{N}$ values interpolated by ordinary kriging perform well. The drawback to ordinary kriging is that it causes smoothing effects and has some difficulty dealing with co-variables. The authors further indicated that ordinary kriging has advantages over other interpolation methods when the study region is relatively flat and uniform, like our field in this study. Kriging is a form of linear least squares estimation and assumes a constant but unknown mean. Kriging weights the surrounding measured values as a measure of distance for prediction of an unmeasured location. The general formula is as follows Equation 5:

$$
Z\left(s_{o}\right)=\sum_{i=1}^{N} \lambda_{i} Z\left(s_{i}\right)
$$

Where:

$$
\begin{aligned}
& Z\left(s_{i}\right)=\text { The measure value at the } i^{\text {th }} \text { location } \\
& \lambda_{i}=\text { An unknown weight for the measured value at } \\
& \text { the } i^{t h} \text { location } \\
& s_{o}=\text { The prediction location } \\
& N=\text { The number of measured values }
\end{aligned}
$$




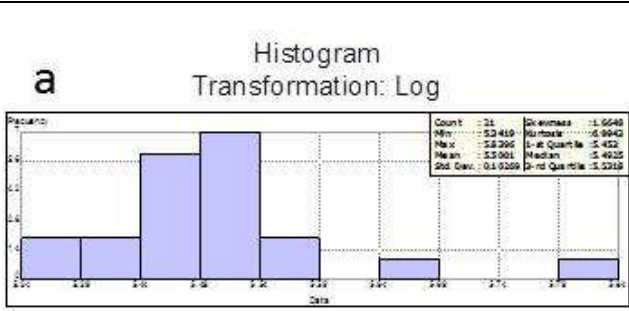

Data Source: thiessen Attribute: weoc

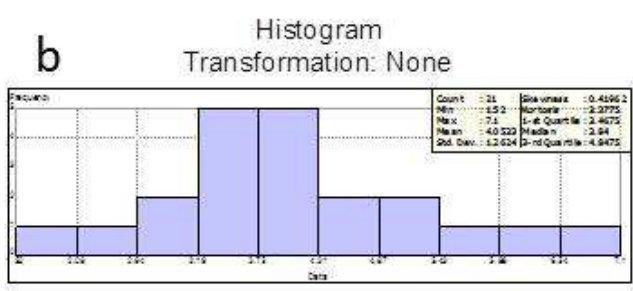

Data Source: thiessen Attribute: $\mathrm{NO} 3 \mathrm{NH} 4$

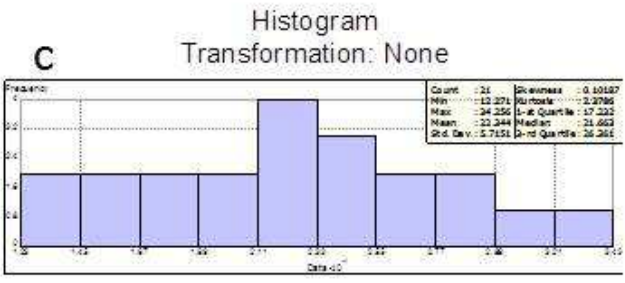

Data Source: thiessen Attribute: Solvita $1 d$

Histogram

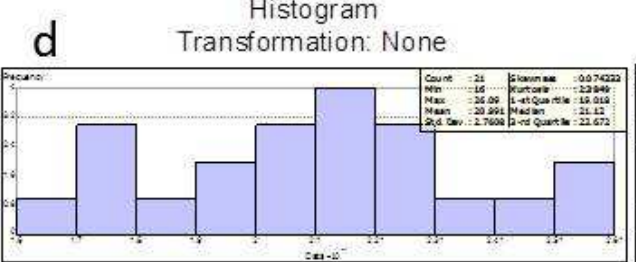

Data Source: thiessen Attribute: WEN

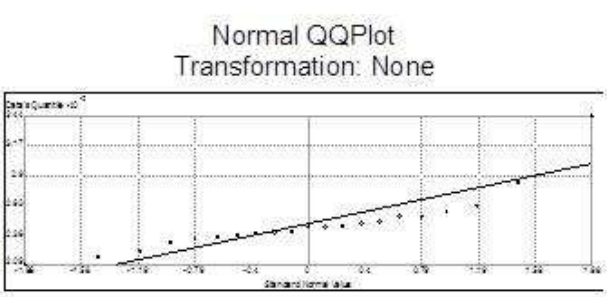

Data Source: thiessen Attribute: weoc

Normal QQPlot

Transformation: None

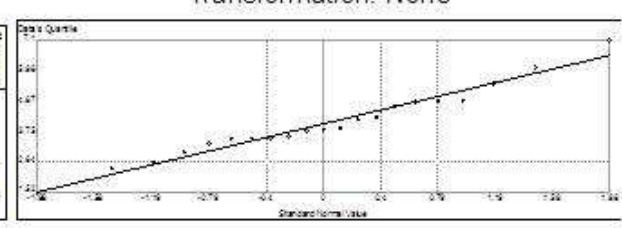

Data Source: thiessen Attribute: NO3 NH4

Normal QQPlot

Transformation: None

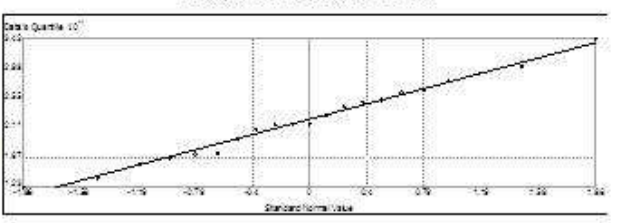

Data Source: thiessen Attribute: Solvita 1d

Normal QQPlot

Transformation: None

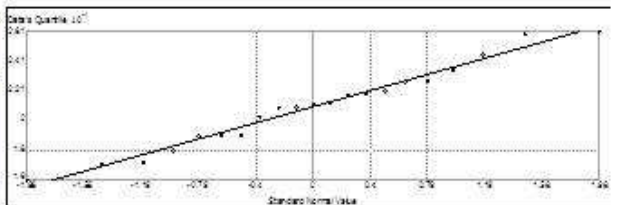

Data Source: thiessen Attribute: WEN

Fig. 4. Histograms and normal QQ plots of soil test attributes

Table 1. Soil test analyses results

\begin{tabular}{lcccccr}
\hline Soil attribute & Mean $\mathrm{mg} / \mathrm{kg}$ & Std Dev & Std. Error & Max mg/kg & Min mg/kg & Median $\mathrm{mg} / \mathrm{kg}$ \\
\hline Initial inorganic N & 3.95 & 1.31 & 0.29 & 7.03 & 1.06 & 3.79 \\
Phosphate & 3.96 & 1.04 & 0.23 & 5.65 & 1.80 & 4.07 \\
Water extractable N & 20.99 & 2.76 & 0.60 & 26.09 & 16.00 & 21.12 \\
Water extractable inorganic N & 4.11 & 1.37 & 0.30 & 6.72 & 1.11 & 3.92 \\
One day $\mathrm{CO}_{2}$-C & 22.34 & 5.72 & 1.25 & 34.26 & 12.27 & 21.66 \\
Water extractable organic C & 246.01 & 27.65 & 6.03 & 343.65 & 208.91 & 242.86 \\
\hline
\end{tabular}

The weights are dependent upon the distance between measured points and the prediction location, as well as the overall spatial arrangement of the measured points. In order for kriging to be valid, spatial autocorrelation must exist. In ordinary kriging, the weight depends on a fitted model to the measured points, the distance to the prediction location and the spatial relationships among the measured values (ESRI, 2011).

Kriging was used in ArcGIS for spatial interpolation of values at unsampled locations based on sample data and their spatial structure analyzed using semivariogram analysis. Semivariogram analysis was performed for WEN, 1-d $\mathrm{CO}_{2}$ and WEOC using ArcGIS 10.0. Nugget variance, range, structure variance and sill were used to evaluate spatial structure. The nugget is the variance at lag distance zero and is caused by measurement error or variation at scales smaller than the sampling unit. The sill is the lag distance that defines the range of spatial continuity. Beyond the range, the values are considered spatially unrelated. The difference between the sill and 
the nugget contains the spatial variance. The range of the model varied from 213.4 to $504 \mathrm{~m}$, beyond which no spatial autocorrelation exists. The strength of the spatial structure at the sampling scale is determined using the following Equation 6:

$\%$ strength of spatial structure $=($ Sill - nugget $) /$ sill

Using this relationship, we determined that the strength of the spatial structure for WEN is $100 \%$, because the nugget value is 0 . The strength of the spatial structures for 1-d $\mathrm{CO}_{2}$ and WEOC are less than zero and $21 \%$ indicating that the spatial autocorrelation was not strong. It is possible that a different model would be more suited for analyzing the spatial structure of $1-\mathrm{dCO}_{2}$ and WEOC or additional samples are needed.

Ordinary kriging based on the variogram analysis provided estimates of WEN, 1-d $\mathrm{CO}_{2}$ and WEOC (Fig. 5-7) values for the 6 in depth increment at location which had not been sampled.

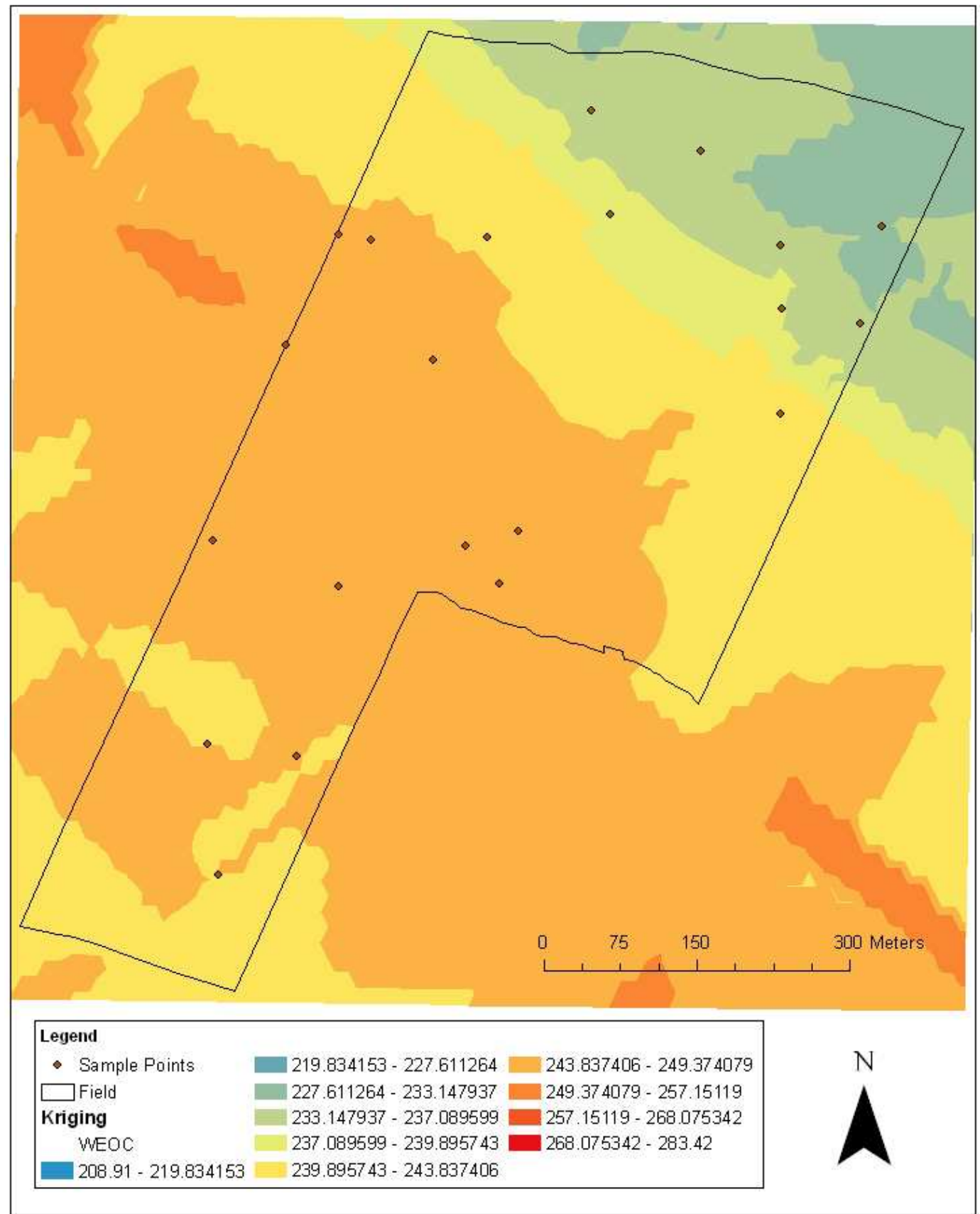

Fig. 5. Kriging results for water extractable organic C (WEOC, $\mathrm{mg} / \mathrm{kg}$ ) throughout the study area 


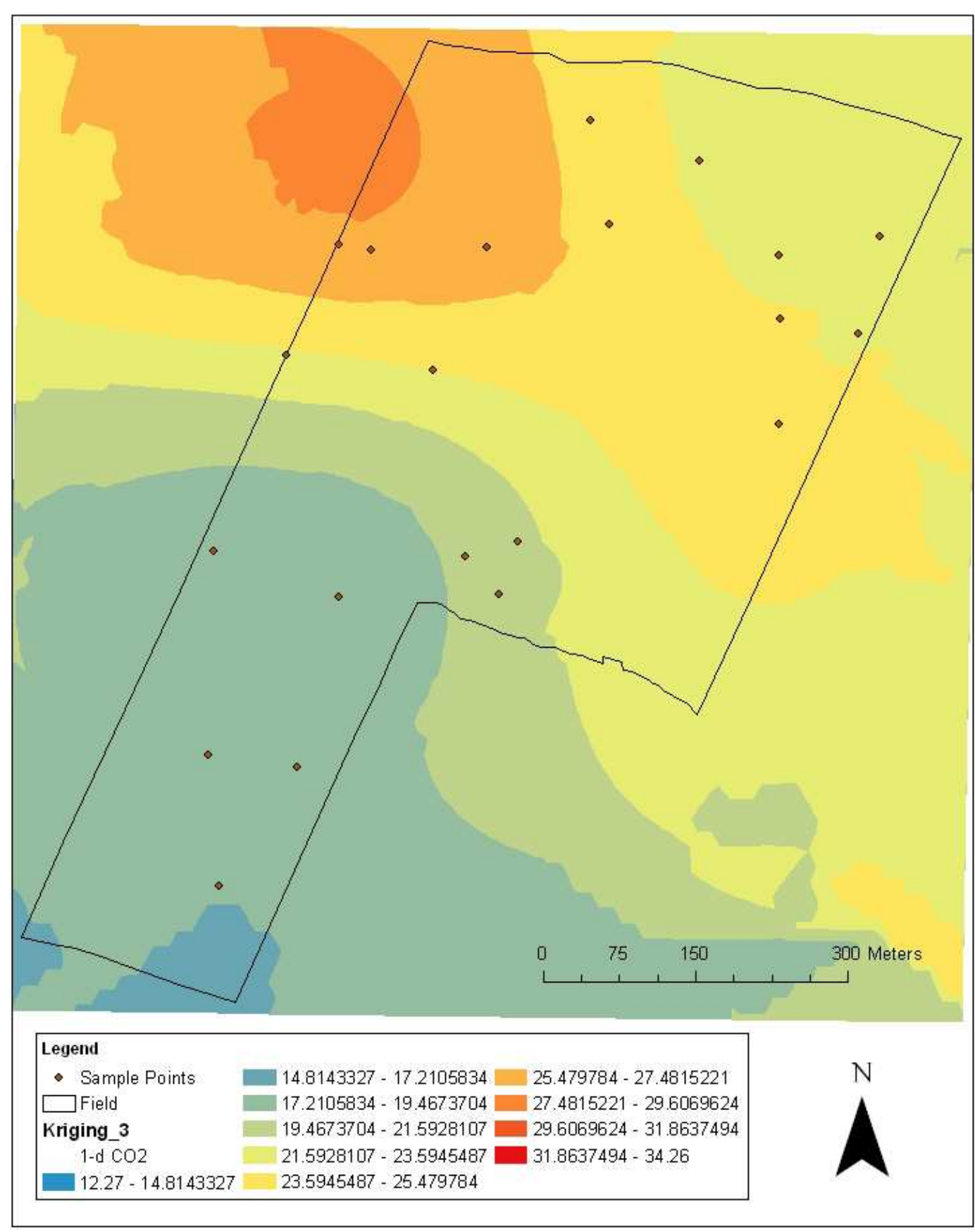

Fig. 6. Kriging results for $1-\mathrm{d} \mathrm{CO}_{2}(\mathrm{mg} / \mathrm{kg})$ analysis throughout the study area

This enables us to develop a map of these values across the study area. When the kriged maps are compared visually with the DEM and aerial photograph of the area, it is apparent the soil values vary with the elevation of the field. WEOC values appear to decrease in a northerly direction, corresponding to a decrease in elevation. WEN and 1-d $\mathrm{CO}_{2}$ values appear to increase at the lower elevation in the northern section of the field and decrease in an outwardly direction from the lowest elevation. An anomalous high WEOC value was present at the lower elevation, which was removed for kriging purposed because it skewed the normality of the data. It is possible that the WEOC values are actually higher in this location, but that this area was not adequately sampled. It makes sense that WEN and 1-d $\mathrm{CO}_{2}$ values would increase with a dip in the elevation as the soil health would be greater in this location due to increased available moisture. 


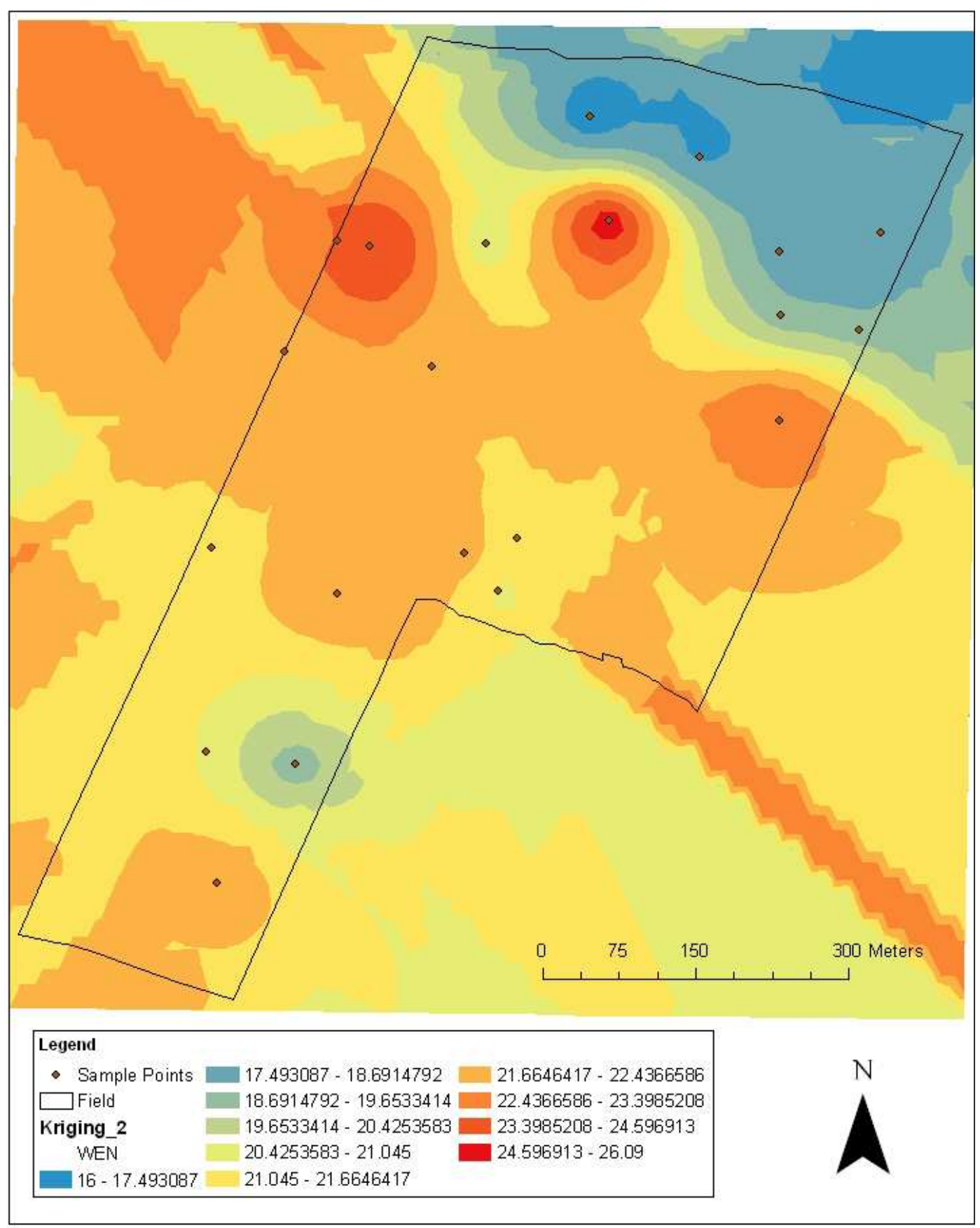

Fig. 7. Kriging results for water extractable $\mathrm{N}(\mathrm{WEN}, \mathrm{mg} / \mathrm{kg})$ throughout the study area

\section{Model Simulation Results}

Initial validation results using actual yield and weather data for 2011 and 2012 indicate that the yield results from the modified $\mathrm{N}$ model were 2.4 and $3.8 \mathrm{Mg}$ $\mathrm{ha}^{-1}$, respectively, while actual yield results were 3.0 and $3.5 \mathrm{Mg} \mathrm{ha}^{-1}$. These results are closer to the actual values than the yield predicted with the SWAT model, which were 1.5 and $0.8 \mathrm{Mg} \mathrm{ha}^{-1}$ for 2011 and 2012, respectively. More actual yield data are needed to determine the validity of these results.

End users of the SWAT model report they receive little to no yield results when no fertilizer is applied during simulation. We found that over 27 years of simulation wheat yield ranged from 0.05 to $3.4 \mathrm{Mg} \mathrm{ha}^{-1}$, with one sample site consistently having higher yields than the others. It is unclear why this site had increased yield over the other sites. The median yield value is near $1.3 \mathrm{Mg}$ 
$\mathrm{ha}^{-1}$, which is low considering the natural fertility of the soil. Fertilizer has not been applied to the field in many years and wheat yields average around $2.0 \mathrm{Mg} \mathrm{ha}^{-1}$. Yield results from wheat rotations with no fertilizer using the modified model ranged from about 1.0 to almost $6.0 \mathrm{Mg}$ $\mathrm{ha}^{-1}$ with an average value around $2.0 \mathrm{Mg} \mathrm{ha}^{-1}$. The modified $\mathrm{N}$ routine increased the range of predicted yield and the median yield. In fact, the range in yield values for all fertilizer treatments increased when using the modified model as compared to the SWAT model. Yield results for each of the 27 years simulated are strongly correlated to $\mathrm{N}$ fertilizer input when using the SWAT model $\left(\mathrm{r}^{2}=0.80\right)$ and show only a weak correlation when using the modified $\mathrm{N}$ model $\left(\mathrm{r}^{2}=0.38\right)$. Multiple linear regression indicates that a linear combination of precipitation, fertilizer application and $\mathrm{N}$ mineralization from the water soluble organic $\mathrm{C}$ and $\mathrm{N}$ pool contributes to predicting yield $(\mathrm{p}<0.05)$. The relationship can be explained by the following Equation 7:

Yield $=30.604+\left(0.139^{\prime}\right.$ Precipitation $)$

$+(0.175 *$ fertilizer $)+(0.290 * N$ mineralized $)$
Use of the multiple linear regression greatly improves the strength of the correlation between yield and determining process values $\left(r^{2}=0.77\right.$, Table 2$)$.

We used the Curve Expert software to fit yield results for varying fertilizer rates from 0 to $335.6 \mathrm{~kg}$ $\mathrm{N} / \mathrm{ha}$, which resulted in a best fit model using a Rational Model (Fig. 8 and 9). Rational functions are used for interpolation in science and engineering when attempting to approximate or model complex systems with diverse behavior. The Rational Model follows the Equation 8:

$y \frac{a+b x}{1+c x+d x^{2}}$

where, $y=$ yield and $x=$ fertilizer application. The SWAT model yield results had a stronger correlation with fertilizer application $\left(y=(13.7+0.8 \mathrm{x}) /\left(1+4.2 \times 10^{-3}\right.\right.$ $\left.\left.\mathrm{x}+9.9 \times 10^{-6} \mathrm{x}^{2}\right), \mathrm{r}^{2}=0.93\right)$ than the modified $\mathrm{N}$ model $(\mathrm{y}=$ $\left.(31.9+1.0 \mathrm{x}) /\left(1+9.0 \times 10^{-3} \mathrm{x}+6.7 \times 10^{-6} \mathrm{x}^{2}\right), \mathrm{r}^{2}=0.79\right)$ when using the Rational Model.

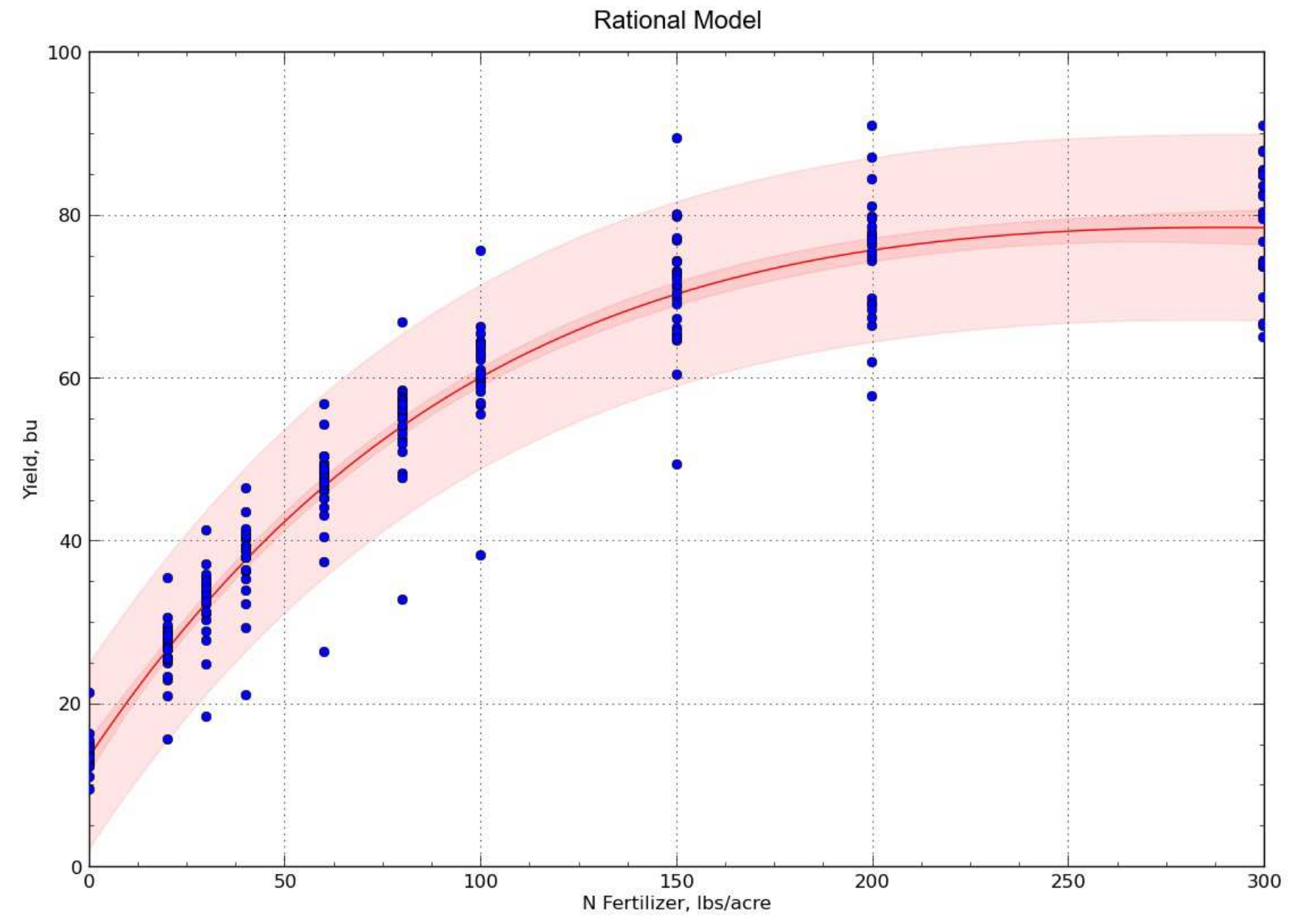

Fig. 8. Rational Model describing the relationship of yield simulation values using the SWAT model with increasing fertilizer application $\left(r^{2}=0.93\right)$ 


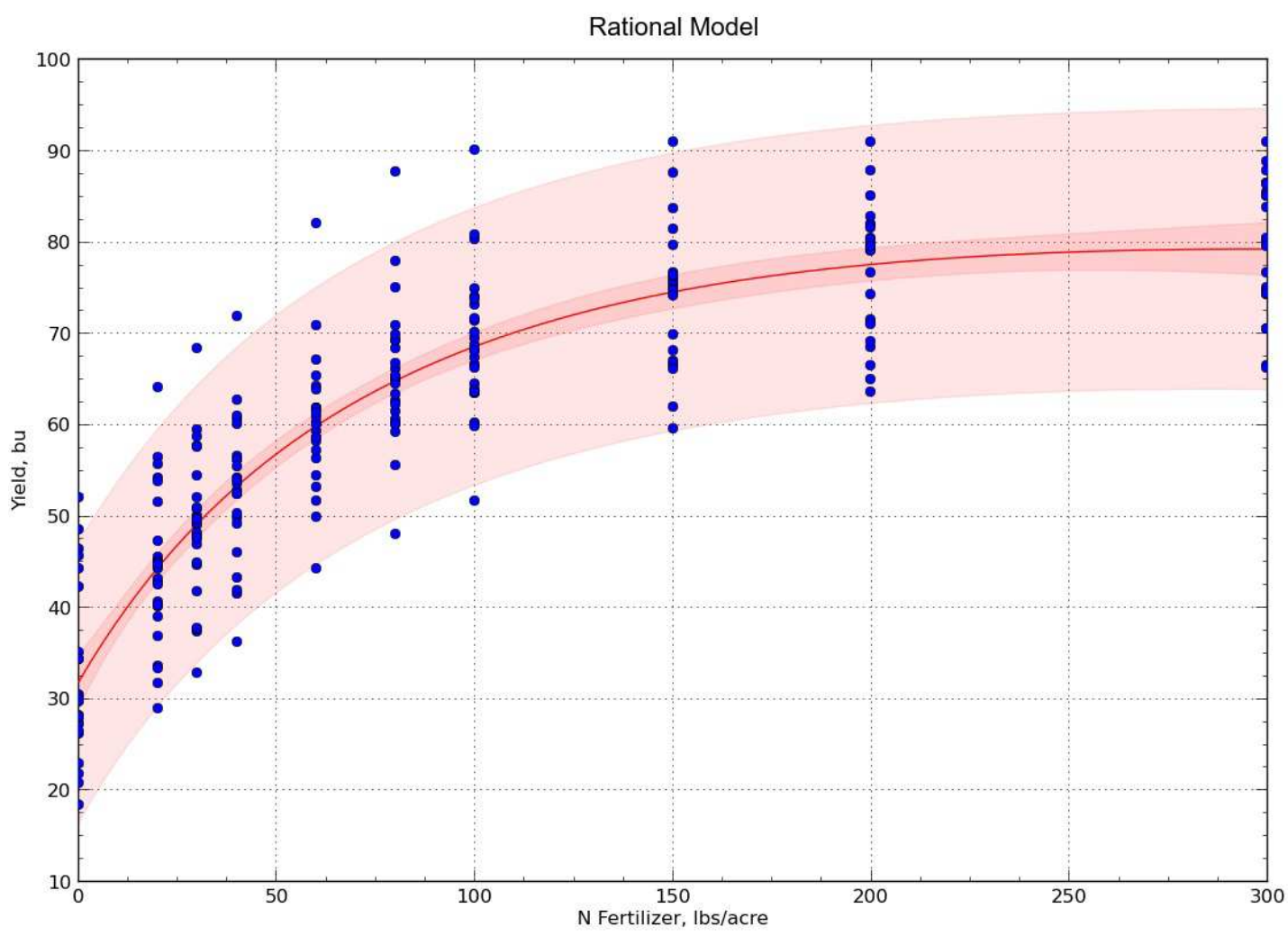

Fig. 9. Relationship between increasing fertilizer application and yield simulated using the modified $\mathrm{N}$ model $\left(\mathrm{r}^{2}=0.79\right)$

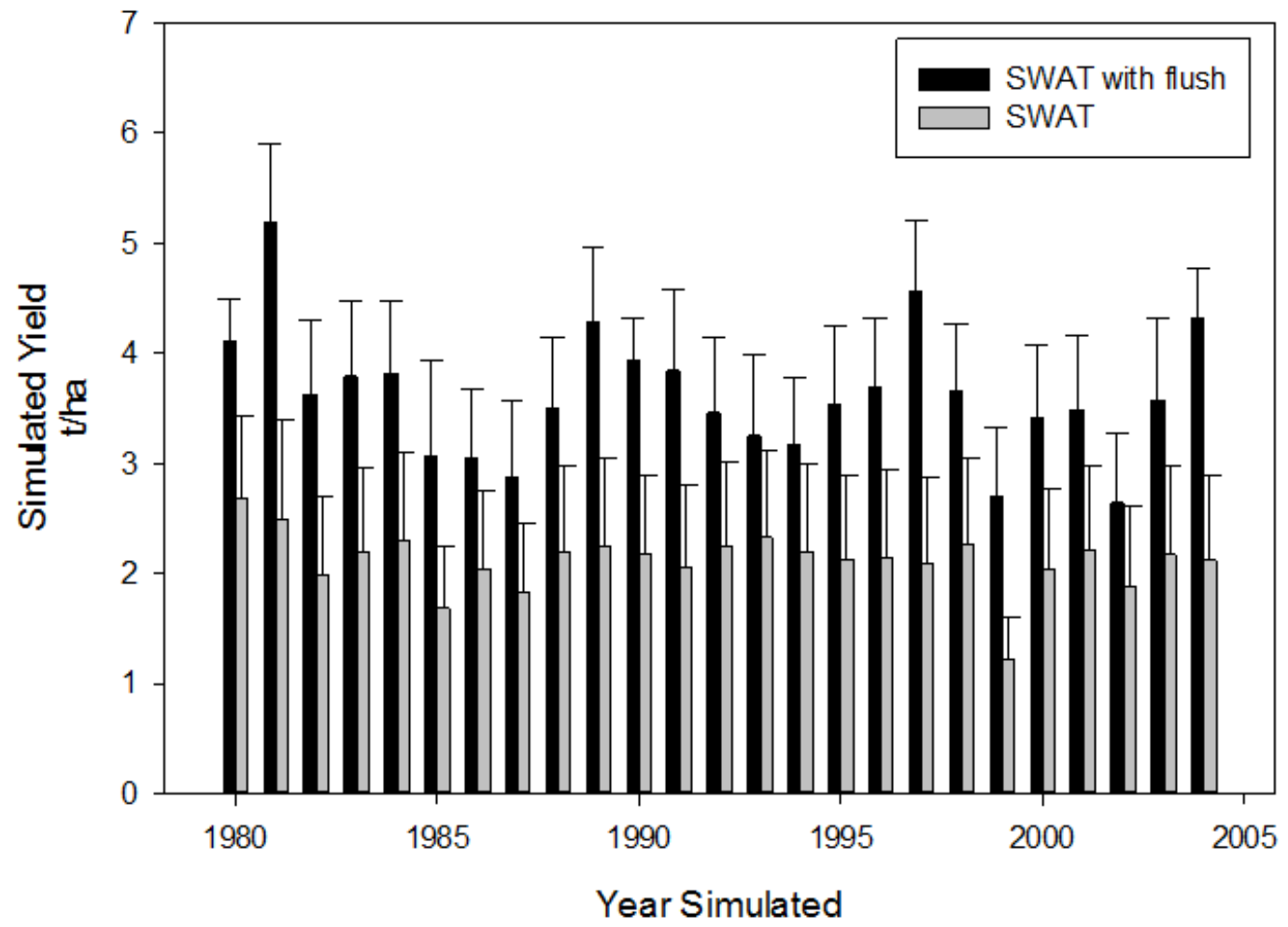

Fig. 10. Wheat yield results by year averaged over all fertilizer treatment simulations using SWAT with the added flush of N and unmodified SWAT 


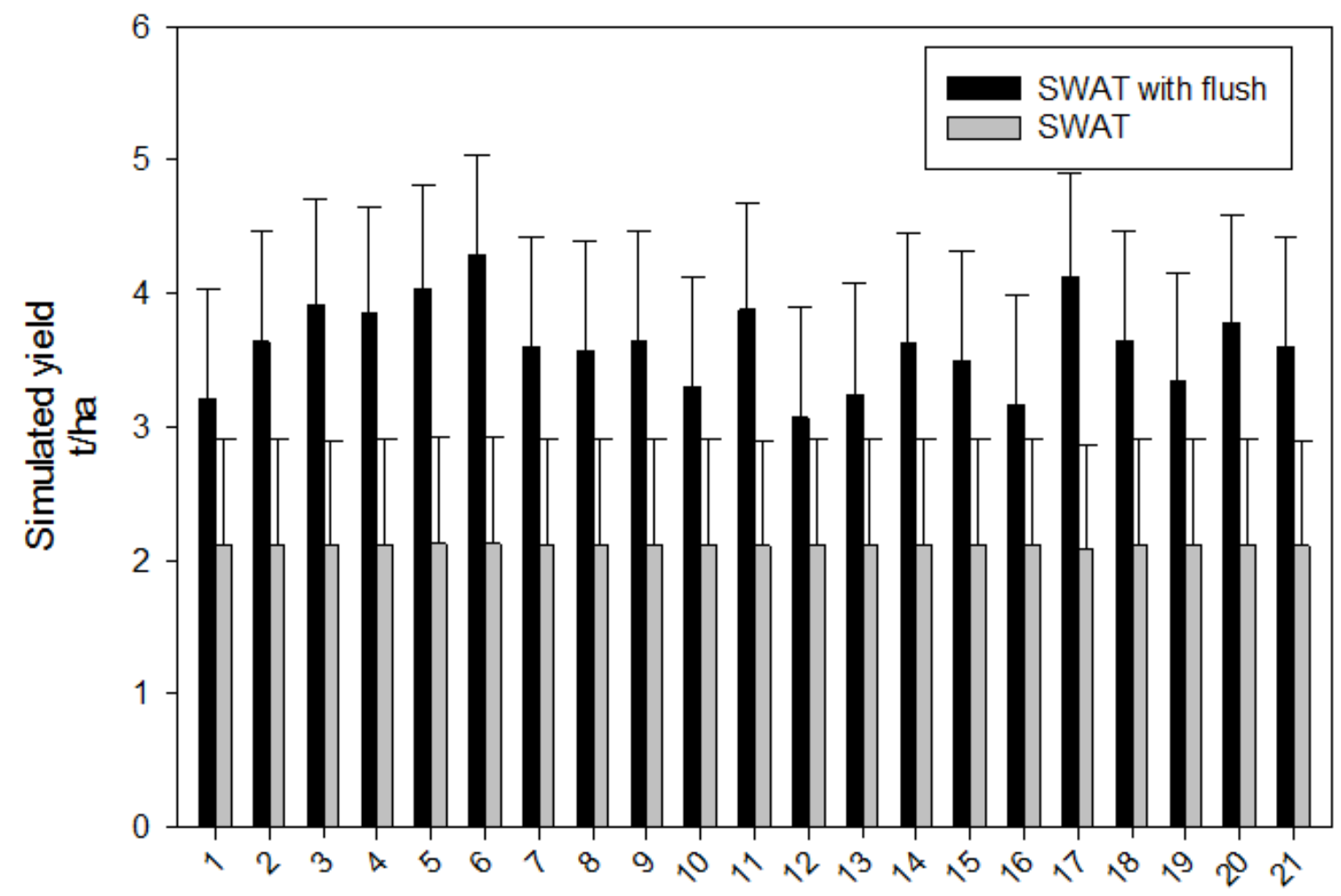

\section{Sample ID}

Fig. 11. Average wheat yield results from 27 years of simulations by soil sample using SWAT with the added flush of N and unmodified SWAT

The yield values obtained varied temporally when using either the SWAT or the modified N model (Fig. 10). Yearly yield values and variability were consistantly higher from the modified $\mathrm{N}$ model than from the SWAT model. The yield values obtained from the modified $\mathrm{N}$ model were also consistantly higher for each soil sample as would be expected with the addition of $\mathrm{N}$ mineralization resulting from microbial activity (Fig. 11). The spatial relationships between yield values from the SWAT model and the modified $\mathrm{N}$ model are depicted in the xyz contour plot in Fig. 12. SWAT simulated yield values indicate that the yield is greater in the southern portion of the field, while simulated yield values using the modified $\mathrm{N}$ model are greater in the northern portion of the field. Analysis using Moran's I for spatial autocorrelation detected significant spatial variability in yield from both models. For the yield data resulting from both the modified and the SWAT model simulations, given the $\mathrm{z}$-score of 85.34 and 85.23 , there is less than $1 \%$ likelihood that the resulting clustered patterns could be the result of random chance.
Because we do not have actual yearly yield data for all 27 years of simulation available for validation, NDVI is being used as a proxy for average yield data for the years 1980 through 2004 in order to determine if the modified model is predicting yield accurately. NDVI greenness factors were compared to kriged yield results from both models. If the model is predicting yield properly, the yield should correspond to greenness in the field. The greenness is an indicator of soil health and viability of plant growth. It follows that if the models are properly simulating $\mathrm{N}$ cycling in the soil, the yield should correspond to the greenness index from the NDVI. The NDVI data for the field indicate that plant growth is greatest in the northern portion of the field at the lower elevations. The simulation model yield results using the modified $\mathrm{N}$ model appear to correspond with the NDVI greenness factor, while the results from the SWAT model do not (Fig. 13). The modified t-test for correlation (Table 3) indicate that both the modified $\mathrm{N}$ and SWAT model yield results are correlated with NDVI values $(p<0.005)$, however, the modified model has a significantly stronger correlation $(\mathrm{p}<0.001)$. 


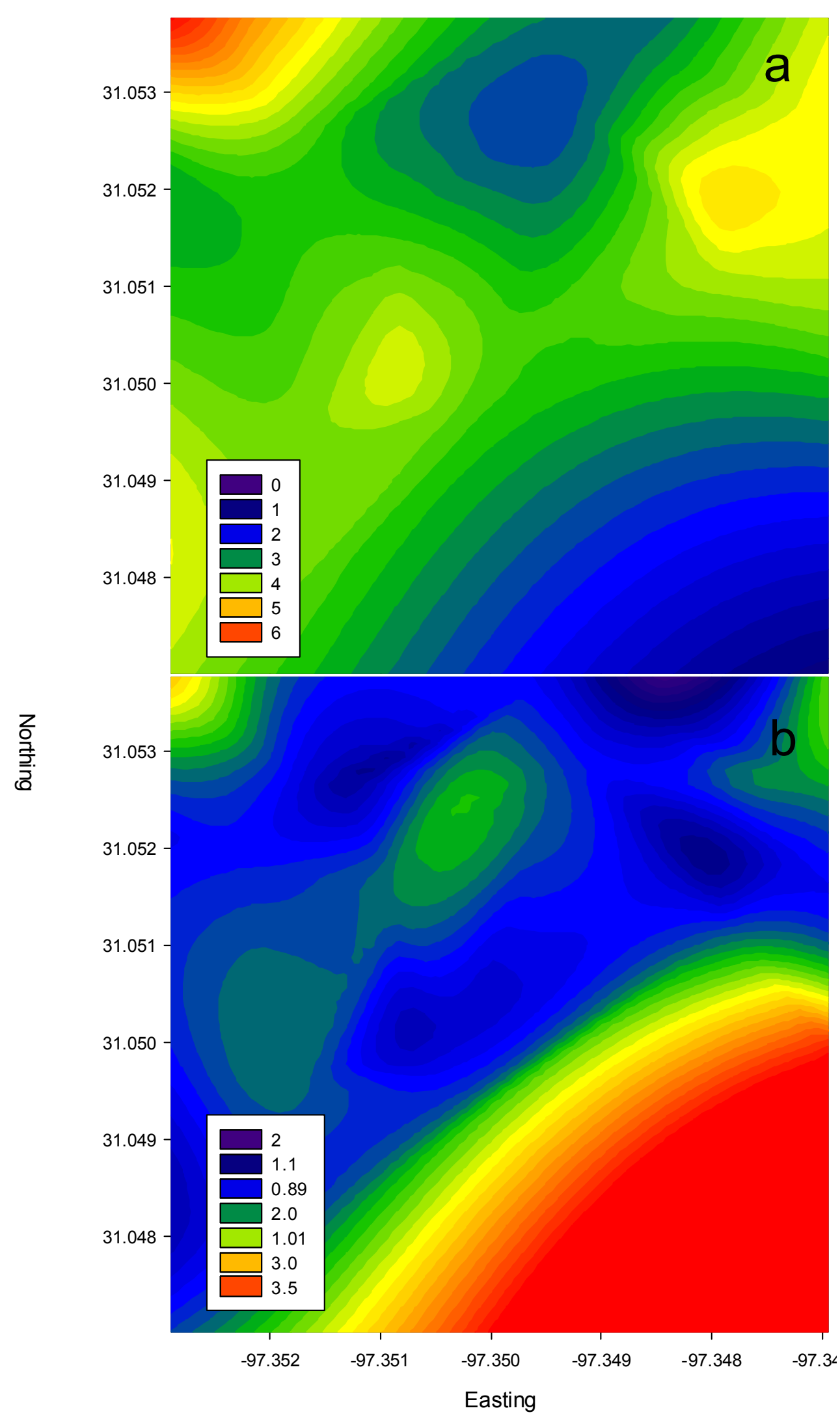

Fig. 12. Wheat yield values ( $\mathrm{kg} / \mathrm{ha}$ ) using the modified $\mathrm{N}$ model (a) and the SWAT model (b) 

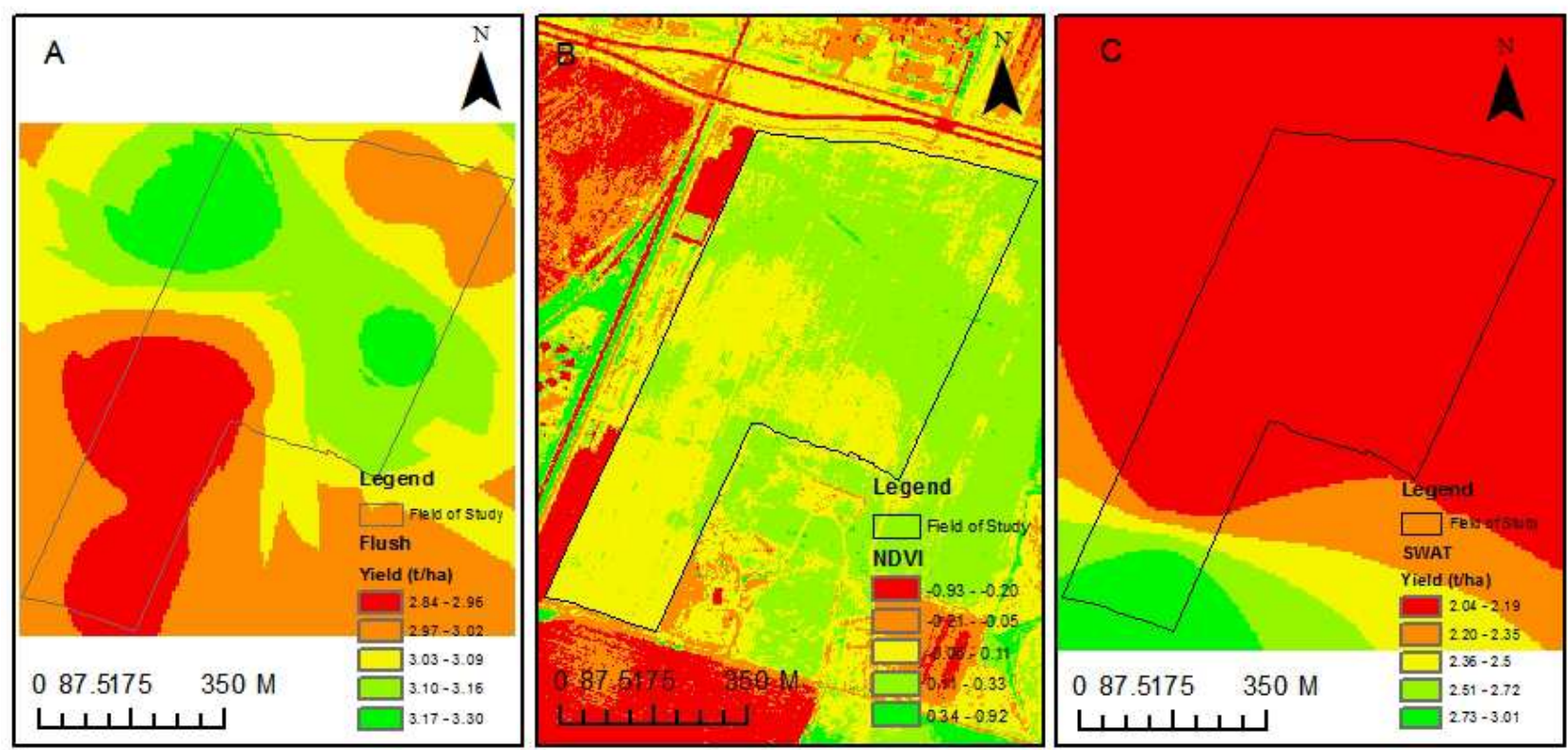

Fig. 13.Kriged yield results from the modified $\mathrm{N}$ model (A) and the SWAT model (C) as compared to normalized difference vegetation Index analysis (B) derived from an aerial photograph of the area

Table 2. Multiple linear regression results for yield, precipitation, $\mathrm{N}$ mineralization and fertilizer application values from the new $\mathrm{N}$ model simulation

\begin{tabular}{llllll}
\hline Coefficient & Std. Error & $\mathrm{t}$ & $\mathrm{P}$ & $\mathrm{VIF}$ & \\
\hline Constant & 30.604 & 0.517 & 59.165 & $<0.001$ & \\
precip_in & 0.139 & 0.0127 & 10.923 & $<0.001$ & 1.007 \\
conv_Fert & 0.175 & 0.00699 & 25.089 & $<0.001$ & 1.317 \\
conv_nmin & 0.290 & 0.00451 & 64.386 & $<0.001$ & 1.324 \\
Analysis of Variance: & & & & & \\
& DF & SS & MS & F & P \\
Regression & 3 & 336369.460 & 112123.153 & 2880.380 & $<0.001$ \\
Residual & 2621 & 102026.404 & 38.927 & & \\
Total & 2624 & 438395.864 & 167.072 & & \\
Column & SSIncr & SSMarg & & & \\
precip_in & 10186.575 & 4644.464 & & & \\
conv_Fert & 164808.621 & 24502.269 & & & \\
conv_nmin & 161374.265 & 161374.265 & & & \\
P & & & & & \\
precip_in & $<0.001$ & & & & \\
conv_Fert & $<0.001$ & & & & \\
conv_nmin & $<0.001$ & & & & \\
\hline
\end{tabular}

Table 3. Modified t-test for correlation between yield results and normalized difference vegetation index values Dutilleul

\begin{tabular}{lllcccc} 
Variable 1 & Variable 2 & Covariance & $\mathrm{P}(\mathrm{Cov})$ & Correlation & Corrected P (Cor) & Effective sample size \\
\hline Modified N routine & SWAT & -4.04 & 0.00005 & -0.51 & 0.00002 & 62.7 \\
Modified N routine & NDVI value & 3.81 & 0.00014 & 0.38 & 0.00009 & 100.3 \\
SWAT & NDVI value & -3.21 & 0.00135 & -0.32 & 0.00115 & 103.1 \\
\hline
\end{tabular}

\section{Discussion}

Statistical results showing a strong correlation between yield and fertilizer inputs resulting from simulation with the SWAT model is problematic and indicates that the
SWAT model is not properly accounting for the natural $\mathrm{N}$ cycling processes in the soil. The relationship between yield, rainfall, $\mathrm{N}$ mineralization and fertilizer when using the modified $\mathrm{N}$ model is a definite improvement over the current $\mathrm{N}$ routines in SWAT as yield is more closely 
reflecting the complexity of the processes involved in plant growth, when all other aspects are held equal. When the Rational Model is used to describe the relationship between fertilization rate and yield, yield values increased accordingly with fertilizer application, eventually leveling off as fertilizer use exceeded needs of the plant. This relationship is expected as the benefits of fertilizer application will cease as plant nutrient stress is completely eliminated by excess available nutrients.

Results from the simulations indicate that yearly yield values and the variability of these yield values were consistantly greater from the modified $\mathrm{N}$ model than from the SWAT model. The yield values obtained from the modified $\mathrm{N}$ model were also consistantly higher for each soil sample as would be expected with the addition of $\mathrm{N}$ mineralization resulting from microbial activity. The spatial variability in yield results by sample increased with the modified $\mathrm{N}$ model as compared to the SWAT model.

In SWAT, soil properties are determined using the soil characteristics obtained from soil survey data. SWAT model output was not sensitive to the changes in the default soil properties associated with the soil series descriptions or elevation changes. In addition, because the $\mathrm{N}$ model in SWAT is based on the very large pools of soil organic $\mathrm{C}$ and $\mathrm{N}$, which are 40 times larger than the active pool of $\mathrm{N}$ and $\mathrm{C}$ that the microbes utilize to cycle $\mathrm{N}$, it is less sensitive to spatial variation of $\mathrm{N}$ mineralization. For example, spatial analyses of soil properties indicate that healthier soil is located at the north end of the field, which corresponds to the lower elevations within the study area. The SWAT model predicts that this area has the lowest yield, when in reality, it has the highest yield. This is due to the fact that yield predicted by the SWAT model are almost solely based on fertilizer input and exclude the natural $\mathrm{N}$ pools that were accounting for in the modified model.

Soil properties are heterogeneous in nature and consist of continuous variables that change over spatial and temporal ranges. Early models describing the processes of $\mathrm{N}$ cycling use simple chemically and spatially lumped models (Manzoni and Porporato, 2009). Some biogeochemical models use a discrete representation of soil layers with different chemical and physical features or a continuous description of nutrient dynamics along the soil profile. What these models fail to do; however, is explicitly describe the spatial dynamics of water, organic matter or nutrients at a horizontally continuous spatial scale over a daily variable time step. The purpose of this study was to develop a $\mathrm{N}$ model that is able to capture the spatially explicit scale of $\mathrm{N}$ cycling over a large temporal range.

The continuous nature of the soil properties being used in the $\mathrm{N}$ cycling model (WEOC, WEON and 1-day $\mathrm{CO}_{2}$ ) allow for spatial interpolation over the field of interest. Because 1-day $\mathrm{CO}_{2}$ analysis is a measure of microbial activity and microbial biomass is the driver of soil C and N cycling (Manzoni and Porporato, 2009) we would expect to see a strong correlation between the soil properties of interest throughout the field. Because the variables are spatially autocorrelated a normal linear regression analysis is inappropriate to examine the relationships between them. Semivariogram analysis of the spatially interpolated soil test results was used examine the spatial structure of the driving factors for $\mathrm{N}$ mineralization. The analysis results indicate that the spatial structures of $1-\mathrm{d} \mathrm{CO}_{2}$ and WEOC values were weak as compared to the spatial structure for WEN. It's possible that a stronger spatial structure may have been obtained by modifying the kriging and semivariogram models used to evaluate the spatial structures of $1-\mathrm{d} \mathrm{CO}_{2}$ and WEOC. Additional soil samples may also have been necessary to accurately capture the spatial variability of these parameters. In addition, the ordinary kriging method used did not account for the possible anisotropic nature of the soil values. Visual assessment of the kriging results indicate that at least some of the spatial variability was related to elevation changes from the north to south; however, this variation was not accounted for in the semivariogram analysis. Topography could potentially impact water extractable soil $\mathrm{C}$ values and microbial activity as assessed using $1-\mathrm{d} \mathrm{CO}_{2}$ analysis, which can regulate $\mathrm{N}$ cycling. Further spatial statistical analyses should include co-kriging analysis with elevation and possibly with vegetation parameters derived from NDVI analysis. Correlation analysis may be useful in further understanding the relationships between soil properties, elevation and vegetation parameters.

Statistical evaluation indicates that the modified $\mathrm{N}$ model is useful in detecting the natural $\mathrm{N}$ mineralization power of the soil. Initial validation results using actual yield and weather data for 2011 and 2012 indicate that the yields were a little high for the zero fertilizer application simulations so some adjustment to the model is needed. The modified $\mathrm{N}$ model does appear to account for spatial variation in soil properties and temporal variation in climate factors. More data are needed over a wider spatial range (regional or larger) to determine how well the modified $\mathrm{N}$ model behaves under various climatic and soil conditions.

\section{Conclusion}

The objective of this study was to quantify the spatial variation of soil biogeochemical factors that affect $\mathrm{N}$ cycling in the soil and use these data to develop a field scale model to determine $\mathrm{N}$ mineralization for integration into the SWAT model. Due to the spatial nature of soil factors, it was essential to use a GIS to collect and analyze spatial and temporal inputs and outputs.

The yield data resulting from the modified model simulation were sensitive to soil changes as well as 
elevation changes. The modified $\mathrm{N}$ model naturally takes into account the spatial variability of soils over geographic areas because as the $\mathrm{C}: \mathrm{N}$ ratio of a soil varies, the MAC_WEON calculation will vary accordingly. In addition, the MAC_WEON calculation used in the modified $\mathrm{N}$ model reflects the variation in soil health spatially by into account the viability of the microbial population. Temporal and climatic variability is accounted for by including the precipitation trigger in the SWAT simulated N mineralization cycle. In addition, soil and climatic variability is accounted for by accounting for microbial activity as measured using the flush of $\mathrm{CO}_{2}$. There is a clear link between "soil health," microbial activity and soil respiration (Franzluebbers, 2016). The equations used to model the complex biogeochemical $\mathrm{N}$ cycling relationships are elegant in their simplicity, yet capture the spatial complexity associated with their processes.

Future studies will need to include long-term yield data for varying soils, crops and management practices in varying climates. Research may also include variations in the approach to data attainment and management for larger projects at the watershed scale. Data acquisition may be challenging for large scale projects as it will not be practical to soil test large areas. Satellite imagery may play a critical role in further development for large-scale simulations. In addition to the impracticality of large-scale soil sampling, only a few laboratories throughout the United States offer the soil tests that the modified $\mathrm{N}$ model is based upon. It will be important to test the use of default values for soil test results and may be necessary to find a proxy for soil test data, possibly using NDVI analysis.

The modified $\mathrm{N}$ model incorporated into SWAT may be useful to regulators to help with the simulation of new conservation practices that include the effect of lower fertilizer inputs on nutrient runoff and pollution. Not only did this study result in an improved $\mathrm{N}$ model, it also succeeded in demonstrating the use of spatial analyses to determine the validity of model input data and output results.

\section{Acknowledgement}

In accordance with Federal civil rights law and U.S. Department of Agriculture (USDA) civil rights regulations and policies, the USDA, its Agencies, offices and employees and institutions participating in or administering USDA programs are prohibited from discriminating based on race, color, national origin, religion, sex, gender identity (including gender expression) $\mathrm{m}$ sexual orientation, disability, age, marital status, family/parental status, income derived from a public assistance program, political beliefs or reprisal or retaliation for prior civil rights activity, in any program or activity conducted or funded by USDA.

\section{Funding Information}

This research was funded with a cooperative agreement funded by USDA-ARS with NRCS agreement number 60-3098-5-006.

\section{Author's Contributions}

Elizabeth Brooke Haney: Primary author and researcher. Responsible for experimental design, research and analysis.

Richard Lee Haney: Laboratory analysis, participated in all experiments, coordinated soil and laboratory analysis and data-analysis.

Jeffrey George Arnold: Organized the study and provided model expertise and analysis. Reviewed and edited the manuscript.

Michael James White: Model expertise and research

Raghavan Srinivasan: Model expertise and research. Reviewed and edited the manuscript.

Scott Allen Senseman: Reviewed and edited the manuscript. Provided technical guidance.

\section{Ethics}

The authors note that there are not any ethical issues that may arise after the publication of this manuscript.

\section{References}

Arnold, J.G., C. Santhi, M. Di Luzio, E.B. Haney and N. Kannan et al., 2010. The HUMUS/SWAT national water quality modeling system. Grassland, Soil and Water Research Laboratory.

Bengtsson, G., P. Bengtson and K.F. Mansson, 2003. Gross nitrogen mineralization-, immobilization- and nitrification rates as a function of soil $\mathrm{C} / \mathrm{N}$ ratio and microbial activity. Soil Biol. Biochem., 35: 143-154. DOI: $10.1016 / \mathrm{S} 0038-0717(02) 00248-1$

Birch, H.F., 1958. The effect of soil drying on humus decomposition and nitrogen availability. Plant Soil, 10: 9-31. DOI: 10.1007/BF01343734

Birch, H.F., 1959. Further observations on humus decomposition and nitrification. Plant Soil, 3: 262-286. DOI: $10.1007 / \mathrm{BF} 01435157$

ESRI, 2011. ArcGIS desktop: Release 10. CA: Environmental Systems Research Institute, Redlands.

Franzluebbers, A.J., 2016. Should soil testing services measure soil biological activity? Agric. Environ. Lett., 1: 150009-150009.

Franzluebbers, A.J., R.L. Haney, C.W. Honeycutt, H.H. Schomberg and F.M. Hons, 2000. Flush of carbon dioxide following rewetting of dried soil relates to active organic pools. Soil. Sci. Soc. Am. J., 64: 613-623. DOI: 10.2136/sssaj2000.642613x 
Franzluebbers, A.J., R.L. Haney, F.M. Hons and D.A. Zuberer, 1996. Active fractions of organic matter in soils with different texture. Soil Biol. Biochem., 28: 1367-1372. DOI: 10.1016/S0038-0717(96)00143-5

Haney, R.L. and E.B. Haney, 2010. Simple and rapid laboratory method for rewetting dry soil for incubations. Commun. Soil Sci. Plant Anal., 41: 1493-1501. DOI: 10.1080/00103624.2010.482171

Haney, R.L., A.J. Franzluebbers, F.M. Hons and D.A. Zuberer, 2004. A rapid procedure for estimating nitrogen mineralization in manured soil. Biol. Fertility Soils, 33: 100-104. DOI: 10.1007/s003740000294

Haney, R.L., A.J. Franzluebbers, V.L. Jin, MV. Johnson and E.B. Haney et al., 2012. Soil organic C:N Vs. water-extractable organic C:N. Open J. Soil Sci., 2: 269-274. DOI: 10.4236/ojss.2012.23032

Haney, R.L., E.B. Haney, L.R. Hossner and J.G. Arnold, 2010. Modifications to the new soil extractant H3A1: A multinutrient extractant. Commun. Soil Sci. Plant Anal., 41: 1513-1523. DOI: $10.1080 / 00103624.2010 .482173$

Haney, R.L., W.H. Brinton and E. Evans, 2008. Estimating soil carbon, nitrogen and phosphorus mineralization from short-term carbon dioxide respiration. Commun. Soil Sci. Plant Anal., 39: 2706-2720. DOI: 10.1080/00103620802358862

Hyams, D., 2013. Curve expert professional v2.0.4. Hixson, TN.

Lauenroth, W.K., F.V. Skogerboe and M. Flug, 1983. Analysis of Ecological Systems: State-of-the-Art in Ecological Modelling. 1st Edn., Elsevier, Amsterdam, ISBN-10: 0444419489, pp: 992.

Legendre, P., M.R.T. Dale, M.J. Fortin, J. Gurevitch and M. Hohn et al., 2002. The consequences of spatial structure for the design and analysis of ecological field surveys, Ecography, 25: 601-615. DOI: $10.1034 /$ j.1600-0587.2002.250508.x

Lillesand, T.M., R.W. Keifer and J.W. Chipman, 2004. Remote Sensing and Image Interpretation. 5th Edn., Wiley, New York, ISBN-10: 0471152277, pp: 763.

Manzoni, S. and A. Porporato, 2009. Soil carbon and nitrogen mineralization: Theory and models across scales. Soil Biol. Biochem., 41: 1355-1379.

DOI: 10.1016/j.soilbio.2009.02.031

Matthews, R.B. and W. Stephens, 2002. Crop-Soil Simulation Models: Applications in Developing Countries. 1st Edn., CABI, Wallingford, ISBN-10: 0851998542, pp: 304.

Metherell, A.K., L. Harding, C. Cole and W. Parton, 1993. Century: Soil organic matter model environment: Technical documentation: Agroecosystem version 4.0. Colorado State University.

Neitsch, S.L., J.G. Arnold, J.R. Kiniry and J.R. Williams, 2001. Soil and water assessment tool theoretical documentation, ver. 2009. Texas Water Resources Institute.
Paul, E.A. and N.G. Juma, 1981. Mineralisation and immobilization of soil nitrogen by microorganisms. Ecol. Bull., 33: 197-204.

Rao, M.N., A.A. Waits and M.L. Neilsen, 2000. A GISbased modeling approach for implementation of sustainable farm management practices. Environ. Modell. Software, 15: 745-753. DOI: $10.1016 / \mathrm{S} 1364-8152(00) 00032-3$

Rosenberg, M.S. and C.D. Anderson, 2011. PASSaGE: Pattern analysis, spatial statistics and geographic exegesis. Version 2. Meth. Ecol. Evolut., 2: 229-232. DOI: 10.1111/j.2041-210X.2010.00081.x

Rouse, J.W., R.H. Haas, J.A. Schell and D.W. Deering, 1973. Monitoring vegetation systems in the great plains with ERTS., Third Earth Resour. Tech. Satell. Symp., 1: 309-317.

Schimel, J.P. and J. Bennett, 2004. Nitrogen mineralization: Challenges of a changing paradigm. Ecology, 85: 591-602. DOI: 10.1890/03-8002

Seligman, N.G. and H. van Keulen, 1981. PAPRAN: A Simulation Model of Annual Pasture Production Limited by Rainfall and Nitrogen. In: Simulation of Nitrogen Behaviour of Soil-Plant Systems, Frissel, M.J. and J.A. Van Veen (Eds.), Pudoc, Wageningen, pp: 192-220.

SSI, 2012. Sigma Plot for Windows, Version 12.5. Systat Software Inc, Germany.

Tate, R.L., 1995. Soil Microbiology. 1st Edn., Wiley, New York, ISBN-10: 0471578681, pp: 398.

Wang, K., C. Zhange and W. Li, 2013. Predictive mapping of soil total nitrogen at a regional scale: A comparison between geographically weighted regression and cokriging. Applied Geography, 42: 73-85. DOI: 10.1016/j.apgeog.2013.04.002

Williams, J.R., 1995. The EPIC Model. In: Computer Models of Watershed Hydrology, Singh, V.P. (Ed.), Water Resources Publications, Highlands Ranch, ISBN-10: 0918334918.

\section{Abbreviations}

1-d $\mathrm{CO}_{2}$, one-day carbon dioxide analysis; $A P E X$, Agricultural Policy/Environmental EXtender Model; ARS, Agricultural Research Service; ASTER, Advanced Spaceborne Thermal Emission and Reflection Radiometer; $C$, carbon; $C: N$, carbon to nitrogen ratio; $C: P$, carbon to phosphorus ratio; $C E A P$, Conservation Effects Assessment Program; $\mathrm{CO}_{2}$, carbon dioxide; $D E M$, digital elevation model; GDEM2, Global Digital Elevation Model version 2; GIS, Geographic Information System; HUMUS/SWAT, Hydrologic Unit Model for the United States/Soil Water Assessment Tool; $M A C$, microbially active carbon; $d$, day; $D / R$, drying and rewetting; $M A C$ WEON, microbially active carbon times the water extractable organic nitrogen; $N$, nitrogen; $N A I P$, National Agriculture Imagery Program; NASA, 
National Aeronautics and Space Administration; NDVI, Normalized Difference Vegetation Index; $\mathrm{NH}^{4+}$, ammonium; $N O^{3-}$, nitrate; $P$, phosphorus; PAPRAN, Production of Arid Pastures limited by RAinfall and Nitrogen; SRTM, Shuttle Radar Topography Mission; TNRIS, Texas Natural Resource Information System; USDA, United States Department of Agriculture; USGS, United States Geological Survey; WEOC, waterextractable organic carbon; WEON, water extractable organic nitrogen; WFPS, water-filled pore space 